\title{
Work Place Empowerment: An Assessment for the Omani Civil Service Agencies
}

\author{
Adil Mohamed Zahran Al Kindy ${ }^{1,2} \&$ Ahmad Jusoh ${ }^{1}$ \\ ${ }_{1}$ Faculty of Management, Universiti Teknologi Malaysia UTM, Johor Bahru, Malaysia \\ 2 Royal Court Affairs, Muscat, Sultanate of Oman \\ Correspondence: Adil Mohamed Zahran Al Kindy. Tel: 968-9935-1106. E-mail: dhab72@hotmail.com
}

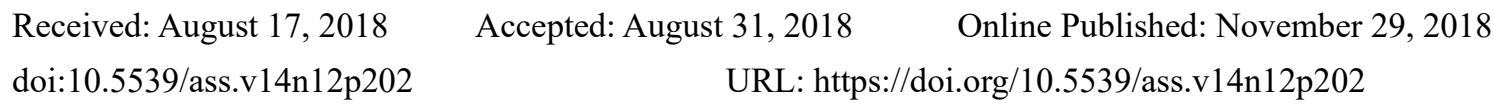

\begin{abstract}
Human resources are the most valuable assent of any organization. However, in general are the least utilized asset in the organizations. Due to economic constraints, organizations are striving to maximize the utilization of their human resources through empowering of their employees. Through empowerment, an organization allows its employees to take the initiative without compromise, and to serve the whole organizational interest with no detailed supervision. Work place empowerment is a combination of the Social Structure Empowerment (SSE) that provides the fundamental climate of empowerment and PE that is associated with individuals' cognitive process. This study focus is psychological empowerment (PE) because it has an active role in overall work place empowerment. Even so, there is a tendency to overlook PE by the organizations since it is not part of the formal organizational process of empowerment and only affects the psychological statues of the employees to their work role. SSE, however, is clearly stipulated in the organizational process and employees terms of reference. Finally, the lack of PE studies in Oman called for further investigation on this variable. Based on quantitative methodology, 458 heads of sections of the Oman Civil Service Agencies (OCSA) completed this study survey. Data was analyzed using the Statistical Package for Social Sciences (SPSS) and Analysis of Moment Structures (AMOS) for Structural Equation Modeling (SEM). The overall results indicated that the heads of sections of OCSA have a high level of the overall PE. In the subscales analysis, the results indicated that competence is the highest state of psychological empowerment as perceived by the heads of sections. Meaning is the second most perceived dimension of PE. Self-determination is the third dimensions of psychological empowerment and Impact is the least perceived subscale of psychological empowerment in this study. However, as revealed by this study, and as compared to the previous studies' findings that, the levels of perception of psychological empowerment by the employee are not equal. Thus, the degree of contribution and influencing of work outcomes is also expected to vary. These results have important theoretical and practical implications for both the researchers and practitioners. For the academic, the results give a picture of the existence of the variables in this area of research. For the practitioners, the results may be used to indicate the areas that require improvement and sustainably by establishing a continuing process of assessment, feedback, and training in their organizations. This study provides recommendations to the Ministry of Civil Services as a practical contribution to the Omani National Plan for the Human Resources Development. The training and employee development plans should focus on employees' empowerment and particularly PE. The Ministry of Civil Services may utilize this information to establish the ground rules for the training for the OCSA employees.
\end{abstract}

Keywords: social structure empowerment, Omani civil service agencies, psychological empowerment, work place empowerment

\section{Introduction}

"An empowered organization is one in which individuals have the knowledge, skill, desire, and opportunity to personally succeed in a way that leads to collective organizational success." - Stephen Covey

\subsection{Overview on Empowerment}

According to Indradevi (2012), human resources are the most valuable asset of an organization, but they are the least utilized. Accordingly, to optimize the utilization of this resource, organizations are striving to empower their employees. Empowering the employees grant them a sense of authority and responsibility and promotes the 
ideal workplace climate to utilize their skills, creativity and abilities.

Human resources are the most valuable assent of any organization, because human resources representing a bank of skills, knowledge, and abilities within the organization, that business competitor cannot imitate (Indradevi, 2012). However, these human resources in general are least utilized asset in the organizations. This issue, the underutilization of the human reassurances, is also one of obstacles that faced by the Omani Civil Service Agencies (OCSA). These organizations are located in Oman, an Arab country located in the Arabian Peninsula. These Organizations provide civil services to the Omani public. Due to economic constraints, organization are striving to maximize the utilization of their human resources. Accordingly, to optimize the utilization of this resource, organizations are striving to empower their employees. However, employees frequently are reluctant of taking this responsibility (Indradevi, 2012). Empowering the employees grant them a sense of authority and responsibility and fosters the ideal conditions for them to utilize their skills, creativity and abilities by accepting accountability for their work. Empowerment facilitates an environment of working together between the leaders and the followers that provides a clear vision of the organizational objectives and expectations, within agreed boundaries (Indradevi, 2012).

The empowerment concepts has been established and advanced by many researchers. Several academics and practitioners for many decades have adopted empowerment as a way of improving decision-making at lower organizational levels meanwhile enriching employees' work environment (Chebat \& Kollias, 2000; Conger \& Kanungo, 1988; Spreitzer, 1995, 1996; Thomas \& Velthouse, 1990). Empowerment is a significant construct since it has a positive impact on work place outcomes for both individuals and organizations (Forrester, 2000; Liden \& Tewksbury, 1995; Spreitzer, 1995, 1996).

Empowerment initiatives have been widely adopted by many organizations within their human resources (Indradevi, 2012; Lawler, Mohrman, \& Benson, 2001; Spreitzer, 2008). Organizations require the competency, ideas, energy, and creativity of every individual member, to be successful in current global business situation. This requirement is across the organization, from low level employees to the higher management and executives. For the organization, one of the ultimate ways to achieve this requirement is through empowerment (O'Toole \& Lawler, 2006). Through empowerment, an organization allows its employees to take the initiative without compromise, to serve the whole organizational interest with no detailed supervision, and to act as if they have the ownership of the organization (O'Toole \& Lawler, 2006). According to Spreitzer (2008), empowerment is divided into two classic approaches; Social-Structural Empowerment (SSE) and Psychological Empowerment (PE).

\subsection{Empowerment Approaches}

According to Maynard, Gilson, and Mathieu (2012), the two main motivational framework used to develop empowerment work are: the job characteristics model of Hackman and Oldham (1980) and work on self-efficacy of Bandura (1977) and Bandura (1982). The two distinct conceptualization of empowerment, structural and psychological, was a result of these two different foundational literatures (Leach, Wall, \& Jackson, 2003; Maynard et al., 2012; Menon, 2001; Spreitzer, 1995).

The Social Structure Empowerment (SSE) is the first approach of empowerment and it is macro level approach. The main focus of this approach is on the social-structural (or contextual) conditions that foster workplace empowerment. On the other hand, Psychological Empowerment (PE) which is the second approach is a micro approach; and its main focus is on the psychological practices of workplace empowerment (Spreitzer, 2008). Further, based on the focus on the empowering structures, policies, and practices and a focus on perceptions of empowerment, the two approaches of empowerment can be differentiated (Eylon \& Bamberger, 2000; Spreitzer, 2008). Moreover, on the issue of theory of empowerment development, each approach, social structure and psychology, plays a significant role in this development (Spreitzer, 2008).

The theories of social exchange and social power are the roots of SSE, Kanter (1977) conducted a typical study on the development of SSE (Spreitzer, 2008). According to Liden and Arad (1996), the social-structural approach concentrates on organizational, institutional, social, economic, political, and cultural force methods that facilitate the environment that fosters workplace empowerment. SSE is a process of individual contribution to the organization, throughout the chain of command. This contribution is based on the improvement of individual access to the following: opportunity, information, support and, resources (Spreitzer, 2008). The focus of empowerment of this study is psychological empowerment and the assessment of its level of existence as perceived by the Omani Civil Service (OCSA) employees.

Social structure empowerment (SSE) is macro level of empowerment and it is stipulated in organizational structure and employees' terms of reface (Spreitzer, 2008). By contrast, psychological empowerment (PE) is a 
micro level of empowerment and it is not stipulated in organizational structure and employees' terms of reface (Spreitzer, 2008). However, the question to be asked here is does SSE independently ensures employees' empowerment, or there are other factors required to ensure employees' empowerment. Many scholars replied to this question that work place empowerment is a combination of the SSE that it provides the fundamental climate of empowerment and PE that is associated with individuals' cognitive process (Appelbaum et al., 2014; Araújo, 2016; Laschinger, Finegan, \& Shamian, 2001; Spreitzer, 2008; Spreitzer, Kizilos, \& Nason, 1997; Martin et al., 2012). Therefore, for this current study the focus is on the micro scale of work place empowerment; that is, the PE for the following reasons: First, social structure empowerment is usually implemented in organizations, including the OCSA, based on organizational structure and it is well defined and understood by the employees. While PE is a perception of empowerment, it is also a cognitive form of empowerment. Despite its active role of PE in overall work place empowerment (Araújo, 2016; Spreitzer, 2008), the tendency of organizations to neglect it because it is not part of a formal organizational administrative process. Thus there is a theoretical and practical demands to focus on this type of empowerment in this current study.

Second, the context of this study is the OCSA. There are few PE studies in Oman. Thus, there is a requirement to conduct an investigation on this type of empowerment in Oman to add knowledge to this research area. This current study is one of the few studies that has been specifically conducted in Oman to investigate the level of existence of PE in OCSA specifically. Among the few studies that have been conducted in Oman, is one by Al-Amri (2013), on the effect of SSE on employees' overall performance. Another study is by Khan (2006), on the role of computer mediated communication in solving collaborative learning empowerment problems in the Omani higher education system. However, neither studies were concerned on PE.

Building from the above, this study is focusing on psychological empowerment because it has an active role in overall work place empowerment. Even so, there is a tendency to overlook PE since it is not part of the formal organizational process of empowerment and only affects the psychological statues of the employees to their work role. SSE, however, is clearly stipulated in the organizational process and employees terms of reference. Finally, the lack of PE studies in Oman called for further investigation on this variable. The investigative question of this current study is "what is the level of existence of PE and its subscales in OSCA". The objective is to determine the overall level of perception of PE and its subscales by the OCSA employees. The two tables in Appendix-A present the general comparison between the two types of empowerment (SSE and PE) and their detailed dimensions and measuring instruments.

\section{Method}

\subsection{Literature Review}

\subsubsection{Psychological Empowerment}

According to Givens (2011) the beginning of the construct of psychological empowerment (PE) was based on the organizational theories of participative management and employee involvement of Cotton (1993) and Wagner (1994) respectively. Empowerment may be described as the "process of enhancing feelings of self-efficacy among organizational members through the identification of conditions that foster powerlessness and through their removal by both formal organizational practices and informal techniques of providing efficacy information (Conger \& Kanungo, 1988, p. 474)". However, Spreitzer (2008) stated that Thomas and Velthouse (1990) followed up Conger and Kanungo (1988)'s concept by the development of the theoretical framework that significantly presents PE as intrinsic motivation, based on four cognitions; competency, self-determination, impact and meaning. These four cognitions mirror their orientation to work.

Thomas and Velthouse (1990) defined PE as a set of cognitions or states influenced by the work environment that helps to create an active-orientation to one's job. PE is a set of psychological states that are necessary for individuals to feel a sense of control in relation to their work (Spreitzer, 2008). This psychological concept pays attention to how employees experience their work role in relation to the organization (Spreitzer, 2008). Another definition, added by Martin Morgan Tuuli and Rowlinson (2009, p. 6) is based on previous studies, "Psychological Empowerment is a constellation of experienced cognitions manifested as sense of meaning, competence, impact and self-determination (Conger et al., 1988; Spreitzer, 1995; Thomas et al., 1990)".

To shed more light on conceptual development of PE, Joo and Lim (2013) stated that Thomas and Velthouse (1990) developed the four cognitive dimensions of empowerment; competence, self-determination, meaning and impact. This development was based on the cognitive motivational content of Deci (1975), Hackman and Oldham (1976), and Bandura (1986). To ensure that the four dimensions truly capture the spirit of PE, the interdisciplinary literature on empowerment was purified, with portrayal on psychology, sociology, social work, and education (Spreitzer, 1997, 2008). Further, Spreitzer (1997) reported wide support for these four 
empowerment dimensions across these dissimilar literatures, and based on these findings; the four dimensions of PE were additionally refined.

\subsubsection{Competence}

Competence, is the self-efficacy specific to one's work, or a belief in one's ability to execute work tasks with the required level of skill (Bandura, 1989; Gist, 1987; Spreitzer, 2008; Srivastava \& Singh, 2008). Competence is also the belief that individuals possess regarding their capability to accomplish their assigned tasks skillfully (Maynard et al., 2012; Srivastava \& Singh, 2008). Without individuals sense of confidence in their abilities, they will feel inadequate when accomplishing their job assignments (Joo \& Lim, 2013).

\subsubsection{Self Determination}

Self-determination is a feeling of choice in initiating and regulating one's actions (Deci, Connell, \& Ryan, 1989; Spreitzer, 2008). It reflects a sense of autonomy or choice over the initiation and continuation of work behaviors and processes, for example, making decisions about work methods, pace, and effort (Bell \& Staw, 1989). It was further described as the feeling of having control (Srivastava \& Singh, 2008). This degree of autonomy or freedom is an essential requirements for a sense of empowerment (Wagner, 1995).

\subsubsection{Impact}

Impact is the degree to which one can influence strategic, administrative, or operating outcomes at work (Ashforth, 1989; Spreitzer, 2008). It reflects the degree to which individuals perceive that their behaviors makes a difference or the degree to which their actions influence the operating system outcomes (Maynard et al., 2012; Srivastava \& Singh, 2008; Thomas \& Velthouse, 1990)

\subsubsection{Meaning}

Meaning comprises a fit between the requirements of one's work role and one's beliefs, values and behaviors (Hackman \& Oldham, 1980; Spreitzer, 2008). Meaning is also the value of work objectives or goals, assessed in respect to an individual's standards, values and ideals (Srivastava \& Singh, 2008; Thomas \& Velthouse, 1990). Thus, meaningfulness focuses on the relations between the values of a task hold and the individual's value system (Srivastava \& Singh, 2008). Meaning may be defined as an individual's extent of caring about a task, and it is the mechanism through which individuals become energized about work. It also plays the role of an empowering engine (Joo \& Lim, 2013; Maynard et al., 2012; Spreitzer et al., 1997).

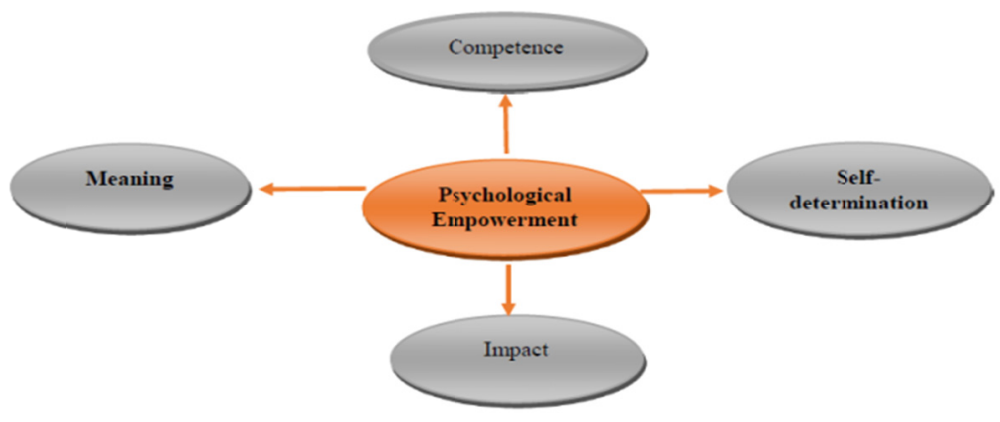

Figure 1. Psychological Empowerment and Its Dimensions

Following from the above, PE is a second order motivational construct manifested in four cognitions: meaning, competence, self-determination and impact (Spreitzer, 1995). The overall construct of PE is comprised of the four dimensions combined (Seibert, Wang, \& Courtright, 2011; Spreitzer, 1995). This construct is associated, theoretically and empirically with important work outcomes through its effect on employees' intrinsic motivation (Hill, Kang, \& Seo, 2014; Seibert et al., 2011). Figure 1 present PE and its dimensions.

Moreover, these four dimensions (cognitions) collectively reflect an active and passive orientation to an individual's work role (Spreitzer, 2008). Empowerment experience is evident in all four dimensions. The absence of any of the four dimensions will have a detrimental effect on the overall level of empowerment such as the reduction of the empowerment level experienced by the employees (Spreitzer, 1995). This was explained by Spreitzer (2008), "if people have discretion to make decisions (i.e., self-determination) but they don't care about the kinds of decisions they can make (i.e., they lack a sense of meaning), they will not feel empowered. Alternatively, if people believe they can make an impact but don't feel like they have the skills and abilities to do their job well (i.e., they lack a sense of competence), they will not feel empowered either. Thus, employees feel 
psychologically empowered when they experience all four psychological states. In this way, empowerment is the 'gestalt 'of the four dimensions (Spreitzer, 2008, p. 57)".

\subsubsection{Antecedents of Psychological Empowerment (PE)}

In order to understand the factors that impact PE, it is important to discuss its antecedents. These antecedents are as follow; the role of leadership, trust, job characteristics or job design, social structure empowerment, individual characteristics and, organizational support (Maynard et al., 2012; Spreitzer, 2008). Due to the importance of these antecedents for the individual level PE at work place, it is essential to explain the role of those antecedents to clarify their contribution to this construct.

\subsubsection{The Role of Leadership}

The role of leadership is one of the most significant antecedent of PE that has the most significant impact on this construct. Example of leadership that has a great influence on PE is transformational leadership (TL). TL was found to strongly related to its flowers' empowerment (Kark, Shamir, \& Chen, 2003; Spreitzer, 2008). Further, Spreitzer (2008) reported that other researchers have replicated the relationship between TL and followers' empowerment (e.g., Avolio, Zhu, Koh, \& Bhatia, 2004; Fuller, Morrison, Jones, Bridger, \& Brown, 1999). In line with this, it was reported by some researches that employees who have developed better relationships with their leader reported greater feeling of empowerment (e.g. , Aryee \& Chen, 2006; Chen, Kirkman, Kanfer, Allen, \& Rosen, 2007; Chen \& Klimoski, 2003; Liden, Wayne, \& Sparrowe, 2000; Spreitzer, 2008; Wallach \& Mueller, 2006; Wat \& Shaffer, 2005). Moreover, many studies have reported that the most examined antecedent of individual work performance is leadership (e.g., Kark et al., 2003; Koberg, Boss, Senjem, \& Goodman, 1999; Liden, Sparrowe, \& Wayne, 1997; Liden et al., 2000; Seibert et al., 2011).

\subsubsection{Trust}

Trust is another antecedent of PE. Followers trust on their leaders has a significant relationship on their feeling of empowerment (Spreitzer, 2008). Trust between followers and their leader found to be effective for empowerment, meaning and competence were predicted by cognition-based trust, while impact was predicted by the effect-based trust (Ergeneli, Gohar, \& Temirbekova, 2007). Another study by Moye, Henkin, and Egley (2005) on teachers and their principals revealed that teachers who had higher interpersonal trust with their principals, found their work to be more meaningful and had significant self-determination and impact. Accordingly, Based on findings from some studies for example, (Ergeneli et al., 2007; Moye et al., 2005), Spreitzer (2008) concluded that followers leaders relationship that is based on support and trust is significant for individuals to experience work place empowerment. Relationships matter for empowerment (Spreitzer, 2008).

\subsubsection{Job Characteristics}

Job Characteristics or Work Design is another antecedent of PE. Job characteristics of Hackman and Oldham were linked by Kraimer, Seibert, and Liden (1999) with the four dimensions of PE (Spreitzer, 2008). Job characteristics are considered to be objective features of the job as per Hackman and Oldham; however the four PE dimensions are considered psychological states which are driven by individual's relation to work (Spreitzer, 2008). The experience of meaning was associated with meaningfulness of job, experience of self-determination was linked with job autonomy, the feeling of competence and impact of PE was more associated with task feedback of job characteristics (Kraimer et al., 1999; Spreitzer, 2008). Other job characteristics are also associated with PE (Spreitzer, 2008). Moreover, Seibert et al. (2011) reported a significant positive relationship between work design and PE at individual-level, and this was the most significant antecedent as revealed by their study (Maynard et al., 2012). Empowering jobs offer the sense of independence and improve the ambiguity that may be induced by having less guidance from others. Weak situation yield type of tension, where employees demanded being proactive to evaluate the situation in order to develop the suitable course of action (Spreitzer, 2008).

\subsubsection{Social Structure Empowerment (SSE)}

SSE is one of the significant antecedent of PE. According to Maynard et al. (2012), the SSE has been considered as one of the main antecedent of PE. Further, studies indicated a significant positive relationship between individual-level PE and high-performance managerial includes SSE (Seibert et al., 2011).

\subsubsection{Individual Characteristics}

Individual Characteristics have their influence on followers' PE. Research findings reported that the degree of feeling of empowerment is stronger on certain people more than others (Spreitzer, 2008). Further, early studies, (e.g. ,Spreitzer, 1995; Thomas \& Velthouse, 1990), reported the significance of individual differences effect on 
the perceptions of PE (Maynard et al., 2012). Moreover, the study by Seibert et al. (2011) on competencies; education, gender, age, tenure, and job level or position, revealed the positive and the significance of these characteristics on PE.

\subsubsection{Organizational Support}

Organizational Support is one of the antecedents of PE. According to Maynard et al. (2012), organizational support concentrates on elements that are a part of the individual's daily activities and include variables such as climate, culture, levels of formalization, and decentralization. The results of 49 studies that linked organizational support to individual PE, were significant and positive (Seibert et al., 2011).

\subsubsection{Outcomes of Psychological Empowerment (PE)}

There are many outcomes of PE, such as: Managerial Effectiveness, Work Related Outcomes, Innovative Behavior and Work Performance. However, according to Spreitzer (1995), the main two consequences of empowerment are: effectiveness and innovative behavior. Further, Maynard et al. (2012) stated that despite the large number of outcomes associated with the PE, the outcomes do appear to blend around two broad categories; performance and affective reactions. The overall outcomes of PE are explain in the following subsequent sections.

\subsubsection{Managerial Effectiveness}

Managerial effectiveness is the extent to which a leader meets or exceeds the expectations of the work role (Spreitzer, 1995). Empowered managers consider themselves competent and are able to influence their jobs and work environments in meaningful ways, therefore, they are likely to both, effectively and proactively perform their job responsibilities. Managers are regarded effective for example, because of their indecency in taking decisions and actions when they anticipating a problem (Spreitzer, 1995). Additionally, for managerial outcomes, empowerment can strongly contribute to these outcomes since work processes cannot merely be based on organizational prescribed rules and procedures (Spreitzer, 1995). To be more specific, empowerment enhances concentration, initiative, and resiliency and thus intensify managerial effectiveness (Spreitzer, 1995; Thomas \& Velthouse, 1990).

Furthermore, according Spreitzer (1995), previous research reported that, each individual dimensions of PE is related to behaviors contributing to managerial effectiveness. "Meaning results in high commitment and concentration of energy (Kanter, 1983). Competence, results in effort and persistence in challenging situations (Gecas, 1989), coping and high goal expectations (Ozer \& Bandura, 1990), and high performance (Locke, Frederick, Lee, \& Bobko, 1984). Self-determination results in learning, interest in activity, and resilience in the face of adversity (Deci \& Ryan, 1987). Impact is associated with an absence of withdrawal from difficult situations and high performance (Ashforth, 1990). Thus, given the effect of each dimension on effectiveness-related outcomes (Spreitzer, 1995, p. 1448)".

\subsubsection{Work Related Outcomes}

A broad spectrum of researches revealed that empowerment benefits both individuals and their organization. Further, results of studies of work place empowerment of individuals, revealed the positive work outcomes from these individuals (Spreitzer, 2008). Furthermore, according to Spreitzer (2008), many studies on the relationship between empowered individual and job satisfaction reported a positive results (Aryee \& Chen, 2006; Carless, 2004; Koberg et al., 1999; Liden et al., 2000; Seibert, Silver, \& Randolph, 2004; Sparrowe, 1994). Empowered employees also showed greater levels of organizational commitment (Avolio et al., 2004; Liden et al., 2000). Empowered employees also showed less tendency to turn over (Koberg et al., 1999; Sparrowe, 1994), and also reported less job strain (Spreitzer et al., 1997).

According to Spreitzer (2008), studies to determine the ways that each of the four dimensions of empowerment predicts work outcomes revealed the following: The meaning and to a lesser degree competence dimensions are strongly predictors of job satisfaction (Spreitzer, 1997). Career progression intentions was associated with the meaning dimension of PE, while the two predictors of organizational commitment were self-determination and impact dimensions (Kraimer et al., 1999). The fact that supports the belief of a 'gestalt' of empowerment being essential to reach the range of outcomes is that different dimensions of empowerment are associated with the diversity of outcomes (Spreitzer, 2008). Additionally, none of the four dimensions, individually has the capacity to influence the broad range of outcomes that are related to the overall construct of PE (Spreitzer, 2008).

\subsubsection{Innovative Behavior}

According to (Spreitzer, 1995), innovative behaviors reflects the creation of something new or different. 
Innovative behaviors are involving the creation of a new product, service, idea, procedure, or process (Woodman, Sawyer, \& Griffin, 1993). Most generally, innovative behaviors are contributed by intrinsic task motivation (Redmond, Mumford, \& Teach, 1993).

Because empowered employees strongly believe that they have the autonomous and have an impact in their work, they are expected to be creative; their feel of constrain is less in comparison to employees who procedural bounded to work (Amabile, 1988; Spreitzer, 1995). Further, empowered employees have high sense of self-efficacious and thus, they are expected to have an innovation at work place and furthermore are expected to be successful (Amabile, 1988; Redmond et al., 1993). Moreover, Kanter (1983) found that inextricable relationship between PE and innovative behavior.

\subsubsection{Work Performance}

According to Spreitzer (2008), PE was associated with managerial effectiveness (Spreitzer, 1995). Also it was found have a positive relationship with employees' effectiveness (Spreitzer et al., 1997). It was also found to be related to employee productivity (Koberg et al., 1999), and newcomer role performance (Chen \& Klimoski, 2003). The two dimensions that have been found to strongly drive performance are competence and impact (Spreitzer, 2008). Further, Maynard et al. (2012) reported that the four dimensions of PE when tested as combined measure; individual $\mathrm{PE}$ found to have a positive impact on individual performance and Organizational Citizenship Behavior (OCB). Moreover, Seibert et al. (2011) study revealed that these two relationships were positive and significant across the 34 and 17 studies captured in their meta-analysis.

According to Spreitzer (2008), PE is not only associated to positive work attitudes, however, it has also been found to be correlated to a positive work performance. It was reported that employees feel more motivated to perform effectively as a results of their high level of PE (Chen et al., 2007; Chen \& Klimoski, 2003; Liden et al., 2000; Seibert et al., 2004; Spreitzer, 2008). Further, Spreitzer (2008) reported that, for work performance, the requirements dimensions are; competence (skills, knowledge and attitude required to accomplish a task), and impact from a significance previous performance (employee vision their results positively of prior performance; accordingly, perceive the sense to move forward as results of their performance).

Following up from the above, scholars' such as Thomas and Velthouse (1990) have argued that psychological empowered individuals yield high level of work performance in comparison to those who are relatively less empowered (Srivastava \& Singh, 2008). In line with this, Liden et al. (2000) reported that the individual feel of self-worth and confidence in one's job competence is expected to transform into high level of work performance in comparison to less psychologically empowered individuals. Additionally, when individuals have sense of meaning to their job and fulfill their job responsibilities, consequently, they induce a positive impact on motivation and productivity of others within their organizations (Liden et al., 2000). Further, Liden et al. (2000) emphasized that individuals who possess self-determination at work can act uniquely to the requirements of each situation.

In association of PE with the OCB, It was reported that different empowerment subscales are related to different elements of OCBs, for example, the meaning dimension is strongly associated with courtesy; the competence subscale relates to both conscientiousness and sportsmanship; the self-determination dimension relates to altruism; and, the impact subscale is associates with conscientiousness (Spreitzer, 2008; Wat \& Shaffer, 2005). As previously reported, different outcomes of $\mathrm{PE}$ are result of contribution of each of its dimensions, but no single dimension captures the gestalt of empowerment in terms of influencing OCBs (Spreitzer, 2008).

\subsection{Research Method}

Research is a systematic investigation to establish facts or principles or to collect information on a subject investigated (Anderson, 2005; Bryman \& Bell, 2015). To achieve the objectives of this study, the research methodology that followed to answer the research questions will be discussed. The major areas of the research methodology followed in this study are; research design, the target population and sampling with its related procedures, the research survey instrument and its translation, and the pilot testing of the instrument. Also the section will cover the sequential stages and procedures for data collection. In addition, it will discuss the use of descriptive statistics to analyze data and to assess construct validity and instrument reliability for all the measured variables.

\subsubsection{Research Designs}

In this study, the research design methodology processes of Saunders, Lewis, and Thornhill (2012) is adopted as a framework for research design. These processes are as follow: philosophies, approaches, strategies, choice of method(s), time horizons, and techniques and procedures of data collection and analysis are in final stage of the 
whole process. In below subsequent paragraphs the adopted research design for this study will be explained.

This current study followed the pragmatist philosophy, because it is appropriate for conducting a deep examination the variables in this study. Further, Creswell (2013), stated that researchers who elect pragmatism are allowed to have a wide freedom of choice; accordingly, researchers are free to choose the techniques, methods, and procedures of research that are more suitable for their needs and goals.

The predominant research approach of this study is deduction based on Saunders et al. (2012) research approaches. This study utilizes the literature to test the theory of psychological empowerment. Thus, the center of this study is to test the concept presented in its framework. In light of this study research approach, Gill and Johnson (2010) stated that deduction allows the researcher to establish objectives and questions using theory, links them to the model as per the frame work of the study, allows data collection involving a surveying strategy tests and explains causal relationships between variables, to answer the research questions and achieve the research objectives

For this current study, the quantitative research method is suitable to address this research area. A quantitative research method may be utilized by the programmatic philosophy. It is also associated with the deductive approach. Accordingly, the quantitative method is in line with the philosophy and approach of this present study (Saunders et al., 2012). On research strategies as per Saunders et al. (2012) quantitative research is associated with experiment and survey. In case of this study, the survey is used to collect data associated with the variables of this study.

The survey strategy is utilized in this study. This study examines the level of existence of variables. Therefore, it requires the collection of a significant amount of quantitative data that are quantitatively analyzed using statistical techniques. The sample was drawn from the general population of the Omani Civil Services Agencies in Oman (OCSA) and the level of existence of the variables is examined statistically in accordance with the collected data that is based on the survey strategy (ALKindy, 2017).

According to Saunders et al. (2012), researchers have the choice of the research time frame. This current study is concerned with a particular phenomenon (or phenomena) at a particular time; the investigation of work place empowerment. This study data was collected in 2016 and only once in the research time period (snapshot) accordingly, this is a cross-sectional study (ALKindy, 2017). The survey time period was four week, this period was between October and November 2016.

\subsubsection{Target Populations and Sampling Process}

In this study, the population is represented by the Oman Civil Service Agencies (OCSA). The target population is the heads of sections who report directly to the middle managers in OCSA. There are 4439 heads of sections in the 36 OCSA as per the Ministry of Civil Service (2015), thus, these 4439 heads of sections form the target population of this study (ALKindy, 2017).

This current study utilized Krejcie and Morgan (1970) to calculate sample size. For the majority of business and management studies, researchers are satisfied to estimate the population's characteristics within plus or minus 3\% to $5 \%$ of the true values (Saunders et al., 2015). This study requires a sample (S) of 354 of heads of sections based on the provided population size ( $\mathrm{N}=4439)$ confidence level of $95 \%$ and precisian level of $5 \%$ and response distribution of $50 \%$ ( $\mathrm{p}$ and $\mathrm{q})$. This sample size was confirmed $(\mathrm{S}=354)$ by the Sample Size Calculator from the following website (http://raosoft.com/samplesize.html).

On the sampling technique, probability sampling is usually related to survey and experimental research strategies (Saunders et al., 2012). The design of this study is pragmatic quantitative, deductive research, with a survey strategy and cross-sectional time horizon. Thus, probability sampling was used in this study.

Simple random sampling is suitable for a geographically dispersed area if the researcher uses an alternative technique for collecting data in place of face to face interviews (Saunders et al., 2012). In this study the population is spread in a wide geographical area and the method of collecting data and analysis is a quantitative approach that does not require face to face interview data collection, and alternative means such as online, internet, email or smart phone could be utilized in data collection process (ALKindy, 2017).

Based on the sample size of 354 for the heads of sections who are distributed into the 36 OCSA (strata), the research design, and guidelines as per Saunders et al. (2012), it was concluded that a proportionate stratified random sampling is the best approach for this study.

The advantage of stratified sampling for this study is that, the nature of the sample itself already has strata (Saunders et al., 2012) and another advantage is "Dividing the population into a series of relevant strata means 
that the sample is more likely to be representative, as you can ensure that each of the strata is represented proportionally within your sample (Saunders et al., 2012, p. 228)". Following Saunders et al. (2012), for this study, statistical inference must be made from the sample, which does not require face to face contact, and the sample has strata (the 36 OCSA). Accordingly, the most suitable sampling approach for this current study was the proportionate stratified simple random sampling (ALKindy, 2017).

\subsubsection{Survey Instruments}

According to Saunders et al. (2012), questionnaires tend to be used for descriptive or explanatory research Thus, a questionnaire developed based on the research design, research question and research objectives was the instrument used to collect data of this study. For this current study, due to the criticality of questionnaire design, it was decided to adopt questionnaires that had already been used, and had proven well their effectiveness and quality in collecting data in this area of research. The survey tool of this study consisted of two main sections: The first section is demographic questions; and the second section is psychological empowerment (ALKindy, 2017).

Section one of the survey tool, consist of demographic data collection that is related to the respondent. This was information on age, gender, number of years in current position in the current organization, total number of years in OCSA and education level.

The second section of the questionnaire consist of question for measurement of psychological empowerment. It was measured by a 12-item measure of empowerment developed by Spreitzer (1995). The reliability and validity for the four dimensions of psychological empowerment has been established in previous research (Spreitzer, 1995). Four dimensions (meaning, competence, self-determination and impact), and 12 items scale of empowerment were used to measure them, which comprised three items for each of the four dimensions. All the items were measured by using a 5 -point Likert scale from $1=$ strongly disagree to $5=$ strongly agree.

This instrument, Spreitzer (1995), was previously used by many studies (e.g., Givens, 2011; Joo \& Lim, 2013; Li, Zhao, \& Begley, 2015; Maynard et al., 2012; Shah \& Nisar, 2011; Spreitzer et al., 1997; Martin Morgan Tuuli \& Rowlinson, 2009). For the previous studies, the reliability of the items on the basis of which data were collected Cronbach's alpha, for example, were as follows: meaning $=.85$, competence $=.84$, self-determination $=.80$ and impact $=.85$ (Martin Morgan Tuuli \& Rowlinson, 2009). For another study, the Cronbach alphas were as follow: meaning $=0.836$, competence $=0.823$, self-determination $=0.764$ and impact $=0.903$ (Ambad \& Bahron, 2012). And, for the study conducted by Joo and Lim (2013), the reliabilities were; meaning $=.90$, competence $=.83$, self-determination $=.89$, and impact $=.92$.

The instrument was translated into Arabic, because Arabic is the official language used in OCSA. According to Brislin (1970) back translation is the most common method for cross-cultural research to measure the validity of an instrument in conditions where the questionnaires are in more than one language. The purpose of back-translation is to produce equivalent materials in two languages. This English version was translated into Arabic and it was back translated to English. According to Saunders et al. (2012) translating questions into another language requires close attention, especially if the translated question is to be decoded and answered by participants in the way its intended. For this study, the instrument translation was carefully accomplished and, to guarantee that the process was executed correct, the Blaschko and Burlingame (2002)s' three steps method was utilized.

Validity relates to the appropriateness of the measure to assess the construct it purports to measure (Burns \& Burns, 2008). The validity of the instrument for quantitative data refers to the degree to which a scale or the instrument used, measures what it is intended to measure (Saunders et al., 2012). For this study, the most common validly measurement, the content and construct validity, were utilized to measure the questionnaire's validity.

Content validity is the degree to which the measurement device; provides sufficient coverage of the research questions (Rossiter, 2008; Saunders et al., 2012). The two most common approaches to achieve content validity are as follows: One is based on a vigilant definition of the research through the literature review and, the other approach is to utilize a panel of individuals to evaluate if the necessity and the significance of each measurement question in the questionnaire (Saunders et al., 2012). A combination of both approaches were utilized in this study. Through a detailed literature review and the constructed conceptual framework, it was concluded that, the best approach for measuring the constructs (psychological empowerment) of this study was adopting Spreitzer (1995)s' questionnaire that was proven, well tested and which had been utilized in a wide spectrum of studies. The approach, a panel of experts was established to determine the validity of the 12 items in this study and to suggest improvements as required. The panel assessed items in the questionnaire for appropriateness and clarity. 
The outcome of this assessment confirmed that the instrument was an effective and valid measure in the Omani Civil Services Agencies (OCSA) settings and offered some required adjustment to suits the Omani context. After this step was completed the questionnaire was ready for pilot study.

Construct validity refers to the extent to which the measurement questions actually measure the presence of those constructs that are intended to be measured (Patten, (Patten, 2012; Saunders et al., 2012; Tsai et al., 2013). A Confirmatory Factor Analysis (CFA) is utilized to assess the degree of the variables representing a smaller number of constructs (Hair, Black, Babin, \& Anderson, 2010). Accordingly, for this study an overall CFA was conducted to estimate the quality of the factor structure and the designated factor loadings by statistically examining of the fit between the proposed measurement model and the data (Yang, 2005). The details of the values related for construct validity of this study are presented in section three 'Results' of this paper.

Reliability refers to consistency, and it is therefore associated with the strength of the measurement instrument and, in specific, its ability to produce consistent findings at different times and under different conditions (Hair et al., 2010; Klenke, 2008; Tsai et al., 2013). "It differ from validity in that it relates not to what should be measured, but instead to how it is measured (Hair et al., 2010, p. 3)". It is usually measured statistically with a Cronbach alpha, with the acceptable value being greater than .60 (Ennis, 2013; Klenke, 2008). It represents the extent of the internal consistency for a set of items (or constructs), where that data will be collected one time. These conditions suit this current study, and so Cronbach-Alphas approach was utilized to measure the reliability of the instrument in this study. The Cronbach-Alpha values for the pilot test and final questionnaire are presented in subsequent literature.

According to Saunders et al. (2012), pilot testing of a questionnaire is required prior for utilizing it to collect data Accordingly, a pilot test was conducted on the questions of the survey instrument to obtain the respondent feedback. The obtained feedback is used to improve and refine the questions, responses, and format of the questionnaire to enhance its effectiveness.

To achieve the pilot test, the instrument was handed to 48 respondents chosen randomly from Oman Civil Services Agencies in their capacity as heads of sections for their feedback. Based on the provided feedback, minor modifications and an update of the questions were accomplished to enhance the questionnaire's effectiveness. A preliminary analysis using the pilot test data was performed to guarantee that the collected data facilitated the researcher in answering the research questions (Saunders et al., 2012). For this purpose, the Statistical Package for the Social Sciences (SPSS) was used for initial Alpha test of the instrument. The results of this test yielded alpha coefficient values form 0.631 to 0.816 . The value of alpha coefficient of 0.70 is considered good, but if the value is more than 0.60, it is acceptable (Burns \& Burns, 2008; Ennis, 2013; Gill \& Johnson, 2010; Klenke, 2008; Nunnally \& Bernstein, 1994; Sekaran \& Bougie, 2010).

\subsubsection{Data Collection}

Among many approached used to collect data, for this study, the drop and collect questionnaire approach was utilized. This approach was selected due to the difficulties in conducting this type of study in Oman, as indicated by other researchers (e.g., Al Zefeiti, 2017; Common, 2011; Dorfman \& House, 2004). To minimize this difficulty, it was decided to visit the participants and make direct contact and, in addition, to adapt some of the guideline provided by Saunders et al. (2012).

The questionnaires were delivered to and collected from the previously selected sample $(S=354)$ from the target population heads of sections of the 36 OCSA located in Muscat. Many stringent measures and steps were followed to ensure the ease of this process and ensure the quality of the collated data.

Based on the respondent distribution across these agencies, the questionnaires were handed to Managers of Human Resources of OCSA proportionally for their internal distribution. This distributions was based on the proportionate stratified simple random sampling approach. A limited time period of four weeks was provided for the respondents to reply to the questionnaire. To ensure the progress of replying to the questionnaire, a tracking and follow up process was carried out every week by phone calls, email, a visit or a combination of all three. The last step was to collect the questionnaires from the respected Human Resources Managers and to prepare them for the data analysis process.

\subsubsection{Data Analysis}

Data analysis is required to test the hypothesis in order to answer the research questions. In this study the descriptive statistical approach of the data analysis is followed. It is a common method for quantitative business and social research (Frankfort-Nachmias et al., 2008; Saunders et al., 2012). Hence, a number of statistical tools were used, such as SPSS (Statistical Package for the Social Sciences) or AMOS (Analysis of Moment Structures). 
The techniques of data analysis consist of descriptive statistics, and Structural Equation Modeling (SEM).

Descriptive statistics were used for this study to identify distributions of the variables and provide the mean and the standard deviations of the data. There were to measure the mean and the standard deviation of psychological empowerment, and represented the perception of the sample population toward this variables. The higher the mean score, the more common the variable is considered to be demonstrated and the opposite is also true. The lower the standard deviation, the less variance there is among the distribution of score and the opposite is also true.

"Structural Equation Modeling (SEM) is multivariate techniques combining aspects of factors analysis and multiple regression that enable the researcher to simultaneously examine a series of interrelated dependence relationship among the measured variables and latent construct (variate) as well as between several latent constructs (Hair et al., 2010, p. 608)". The latent variables are represented by multiple variables in same way as in factor analysis (Hair et al., 2010). SEM's foundation is based on two multivariate techniques: factor analysis and multiple regression analysis. It may therefore be considered as a unique combination of both types of techniques (Hair et al., 2010).

The highly desirable features of SEM have made it a widely accepted techniques for non-experimental research, where testing methods for theory are not well developed and ethically, it is not feasible to achieve experimental design for the study (Bentler, 1980; Byrne, 2010). Since SEM can be used very effectively to address number of the research problems associated with non-experimental research (Byrne, 2010). Accordingly, this study used SEM to address the quantitative, explanatory, hypothesis testing and non-experimental research, together with the relationship between the variables and the causal effects between the variables.

In general, the SEM model can be broken down into two sub-models: a measurement model, and a structural model (Byrne, 2010). The measurement model is an SEM model that, first, specifies the indicators for each construct. It is therefore associated with latent variables and their indicators, and second, it enables an assessment of construct validity, the first of the two major step in complete structural analysis (Hair et al., 2010). The measurement model is accomplished by using a Confirmatory Factor Analysis (CFA) in which there is unmeasured covariance between each possible pair of latent constructs (Byrne, 2010; Hair et al., 2010).

Byrne (2010) also stated that CFA is utilized in situations where the researcher has some prior information of the underlying latent variable structure. The researcher, based on theoretical or empirical knowledge, or the combination of both, postulates relations between the observed measures and the underlying factors and subsequently tests this hypothesized structure statistically to determine the adequacy of its goodness-of-fit to the sample data (Byrne, 2010). For the purpose of this study CFA was utilized because, this study is measuring a predefined relationship between the latent variable of psychological empowerment and its observable measuring factors (items).

\section{Results}

The results of the data analysis related to this study are presented in this section. For this purpose, SPSS 21 and AMOS 18 were utilized. The arrangement of this section will be as follows; Sample Demographic, Preliminarily Data Screening and Analysis, Measurement Model, Descriptive statistics of the Scale (PE) and overall study findings.

\subsection{Sample Demographic}

\subsubsection{Response Rate}

The calculated sample for this study was $\mathrm{S}=354$, however, more than this sample size of (S-580) questionnaires were distributed to obtain a satisfactory number of samples, after taking into the consideration of the unreturned questionnaires. This large sample distribution was required to counter act the possibility of having a large number of unanswered questionnaires, that was expected due to the common difficulty of conducting this type of research in governmental sectors in Oman and was based on the experience of previous studies (Al-Araimi, 2012; Al Zefeiti, 2017; Al Zefeiti \& Mohamad, 2015; Common, 2011; Dorfman \& House, 2004). In addition, a large samples size is able to minimize sampling error (Babbie, 2012; Barlett, Kotrlik, \& Higgins, 2001; Hezarvand, 2013; Rubin \& Babbie, 2010; Rumsey, 2016). Sampling error defined as a minor differences that exist among samples and between them and the population from which they are drawn (Rumsey, 2016; Simon \& Goes, 2012). Minimizing sampling error helps to maximize the samples' representativeness (Simon \& Goes, 2012). The minimization of the sample error may be achieved by a proper and unbiased probability sampling and by using a large sample size (https://explorable.com/sampling-error, dated 11 March 2017). These two approaches for minimizing sampling error were closely followed in this study. 
To achieve this sample size, a sample (S) of 580 heads of sections of the Omani Civil Services Agencies (OCSA), from a population $(\mathrm{N})$ of 4439 , was chosen to respond to the research survey. This size ( $\mathrm{S}=580)$ was achieved by distributing around $60 \%$ extra questionnaires to the respective OSCA. This percentage $(60 \%)$ was established based on the previous studies conducted in this region. Out of 580 paper questionnaires that were distribute, 466 were returned. That yielded an unexpected response rate of approximately eighty percent $(80 \%)$ as illustrated in Table 1 . A response rate below $50 \%$ represents a minority, reflecting an incorrect generalization of the population. However, for this study, the response rate was above $80 \%$, a satisfactory rate for the purpose of this study (Uma Sekaran, 2003). Further, eight questionnaires (1.7\%) from four hundred and sixty six (466) were rejected from preliminarily data analysis due to $10 \%$ or above questions being unanswered in the survey (Hair et al., 2015). Thus, 458 sets of questionnaires (98.3\%) were used in this study to reply to the research question.

Table 1. Return and Usable and Unusable Rate of the Questionnaires

\begin{tabular}{ccccc}
\hline Survey Method & & Questionnaires & Number of Response & Percentage (\%) \\
\hline \multirow{4}{*}{ Paper Survey } & Return Rate & Distribution & 580 & 100 \\
& & Return & 466 & 80 \\
& Usable Rate & Un returned & 114 & 20 \\
& & Return and Usable (not defective) & 458 & 98.3 \\
& & Return and Un-Usable (defective) & 8 & 1.7 \\
\hline
\end{tabular}

\subsubsection{Demographic and Characteristics of the Respondent}

The sample collected in this study varied in personal and respondent characteristics. The demographic information that includes age, gender, total work experience, work experience in the capacity of heads of sections and qualification are provided in Table 2 for general knowledge on the respondent characteristics, and are not part of the analysis.

Table 2. Demographic Profile of Respondents

\begin{tabular}{|c|c|c|c|}
\hline Demographic Profile & & Frequency & Percent \\
\hline \multirow{3}{*}{ Gender } & Male & 271 & 59.2 \\
\hline & Female & 187 & 40.8 \\
\hline & Total & 458 & 100.0 \\
\hline \multirow{5}{*}{ Age } & $20-29$ & 40 & 8.7 \\
\hline & $30-39$ & 280 & 61.1 \\
\hline & $40-49$ & 105 & 22.9 \\
\hline & $>50$ & 33 & 7.2 \\
\hline & Total & 458 & 100.0 \\
\hline \multirow{6}{*}{ Total Experience in OCSA } & $1-5$ & 61 & 13.3 \\
\hline & $6-10$ & 155 & 33.8 \\
\hline & $11-15$ & 93 & 20.3 \\
\hline & $16-20$ & 52 & 11.4 \\
\hline & $>20$ & 97 & 21.2 \\
\hline & Total & 458 & 100.0 \\
\hline \multirow{6}{*}{ Current Experience as heads of sections } & $1-5$ & 155 & 33.8 \\
\hline & $6-10$ & 220 & 48.0 \\
\hline & $11-15$ & 39 & 8.5 \\
\hline & $16-20$ & 22 & 4.8 \\
\hline & $>20$ & 22 & 4.8 \\
\hline & Total & 458 & 100.0 \\
\hline \multirow{7}{*}{ Qualifications } & less than high school & 9 & 2.0 \\
\hline & High school & 56 & 12.2 \\
\hline & Diploma & 74 & 16.2 \\
\hline & Bachelors & 261 & 57.0 \\
\hline & Masters & 54 & 11.8 \\
\hline & $\mathrm{PhD}$ & 4 & .9 \\
\hline & Total & 458 & 100.0 \\
\hline
\end{tabular}




\subsection{Preliminarily Data Screening and Analusis}

Since this study utilized a self-administered questionnaire (Hezarvand, 2013; Highman, 1955; Saleh, 2006), response error was an issue, because the researcher of this study, did not have any control or influence on the way it was accomplished. Past investigations in the social science indicate that response scores on self-reported surveys do not accurately reflect scores: thus, there are response errors (Chase \& Godbey, 1983; Chase \& Harada, 1984; Phillips \& Clancy, 1972; Wyner, 1980). Data examination is recommended before conducting of SEM analysis, for example, checking sample size and missing data, looking for outliers, for unengaged response, testing for normality, common method bias and so on (Ullman \& Bentler, 2003). Further, Byrne (2010) stressed the importance of checking requirements of the data being of a continuous scale and having a multivariate normal distribution. Therefore, a series of steps were performed to ensure the accuracy in data examination and preparation. These steps are detailed is this subsection.

\subsubsection{Data Editing and Coding}

After data collection from OCSA, the initial process of editing of data took place to ensure data omission completeness and consistency. The next step was to code the questions in the questionnaire and establish the data file is SPSS. Each question was assigned a code for the variables of the study. The coding of the questions represented the variables and related subscales. The associated reply were also assigned a code to represent the likert scale in case of the 12 questions or the related reply in case of the five demographic questions

\subsubsection{Data Screening}

To ensure the level of accuracy in the data entry process, the double action process was conducted. Case by case process of verification was accomplished as the first action immediately after receiving of the surveys questionnaires. The second process was accomplished after the data coding, by the utilizing the descriptive statistics such as frequency distribution, mean and standard deviation. The process, for example, included the check for missing data and respondent non engagement. The process revealed systematic missing data of $10 \%$ or above, and responses with randomly missing data.

\subsubsection{Examination of Data Entry and Missing Data}

One of the persistent problem in data analysis is missing data (Tabachnick \& Fidell, 2007). Therefore, process of data analysis is accomplished through the assessment of data entry and handling of missing data. This is an important process to gain vital information regarding the data characteristics and analysis (Hair et al., 2010). From Table 1, it can be established that 466 of the returned questionnaires revealed the following: First, eight questionnaires from four hundred and sixty six (466) were omitted from preliminarily data amylases (1.7\%) because, these eight questionnaire revealed $10 \%$ or above of unanswered questions, mainly systematic missing data (Hair et al., 2015). The deletion of eight questionnaires yielded the balance of 458 questionnaires for further assessment. Second, the examination of the balance of 458 questionnaires, revealed that eight of the 458 had random missing data between 1.5 to $4.4 \%$ (1 to 3 questions). Therefore, a mean imputation technique was used to replace those missing values by replacing the missing values with the mean of each item (George \& Mallery, 2006). In summary, after the deletion of eight questionnaires (1.7\%) with $10 \%$ missing data, and the treatment of another eight with random missing data of $1.5-4.4 \%, 458$ usable questionnaires were retained for the next step of assessment of normality and outliers.

\subsubsection{Assessment of Outliers}

In order to carry out an SEM analysis, it is essential to ensure that the data is normally distributed (Byrne, 2010). As non-normal distribution may be attributed to the presence of outlier cases in the data. B. Tabachnick and Fidell (2007) argued that an outlier may be a univariate outlier in case of an extreme value on one variable or multivariate outlier as presented by a strange combination of scores on two or more variables. The results of outliers is the distortion of statistics. Accordingly, for this study, a process of assessment of normality and outlier cases was conducted, the results are presented in the subsections below.

\subsubsection{Unengaged Respondent}

The items on the questionnaire were measured against unengaged respondents. Such responses are associated with univariate outliers. Unengaged respondents are those participants who reply to the questionnaire without deviation within the answers (Lange \& Steck, 2014). Accordingly, unengaged responses were checked if any, through the use of standard deviation. After calculating the standard deviations within the survey questions of all participants, it was confidently established that unengaged respondents are not an issue in the analysis of this study. The unengaged responses usually have very low value of standard deviation (Lange \& Steck, 2014; Little \& Rubin, 2014). 


\subsubsection{Univariate Outliers}

One of the common methods used to assess outliers is to use criterion based on $z$-scores (Cousineau \& Chartier, 2015; Seo, 2006). Accordingly, SPSS 21 was used to detect the presence of outlier using z score calculation. Any item that has an absolute value of more than $3.29(\mathrm{z}> \pm 3.29)$, it will be considered as an outlier and will be subjected of deletion or treatment (Bedi, Cooper, \& Haney, 2013; Bottaro, Heyward, Bezerra, \& Wagner, 2002; Den Hartog, Derix, Van Bemmel, Kremer, \& Jolles, 2003; Lekander et al., 2011; B. G. Tabachnick \& Fidell, 1996; Barbara G Tabachnick, Fidell, \& Osterlind, 2001). For this study, the initial examination revealed 49 observations that have $\mathrm{z}$-score above $3.29(\mathrm{z}> \pm 3.29)$, hence, these were deleted from the total of 458 . The remaining 409 observation were used for further analysis.

\subsubsection{Multivariate Outliers}

A common approach to test for of multivariate outliers is the calculation of the squared Mahalanobis distance (D2) for each case (Byrne, 2013; Hezarvand, 2013). Thus, this method was used to detect multivariate outliers by SPSS 21. A multivariate outlier would exist if the probability was below $0.001 \quad(p<.001)$ (Rovai, Baker, \& Ponton, 2013). Observations that reach this significant threshold may be prone to elimination. The assessment, revealed two observations with values below .001 $(\mathrm{p}<.001)$, so, these two were removed, and the analysis proceeded with 407 observations.

\subsubsection{Assessment for Normality}

One of the methods utilized to check for deviation from normality is to use skewness and kurtosis. In this method, the values for skewness and kurtosis should not be significant for the distribution to be normal. According to Kline (2010) with generous guidelines, skewness and kurtosis should not exceed the absolute value of 2 and 8 , respectively. This was well met for the all the items under consideration in this study. Hence, it can be concluded that all the items fall within the recommended range to indicate univariate normality The issue of normality is less sensitive in large sample sizes, for example, in this study $\mathrm{N}=407$. According to Hair et al. (2010), for a large sample size, 200 and above, even minor deviations from normality can be significant but not substantive. Despite the fact of a larger sample as per above explanation, the sample of this study satisfied the univariate normality as it appears in Table 3.

Table 3. Descriptive Statistics-Univariate Normality

\begin{tabular}{ccccccccc}
\hline \multirow{2}{*}{ N=407 } & Minimum & Maximum & Mean & Std. Deviation & \multicolumn{2}{c}{ Skewness } & \multicolumn{2}{c}{ Kurtosis } \\
\cline { 2 - 8 } & Statistic & Statistic & Statistic & Statistic & Statistic & Std. Error & Statistic & Std. Error \\
\hline PEC1 & 3 & 5 & 4.59 & .526 & -.731 & .121 & .718 & .241 \\
PEC2 & 3 & 5 & 4.59 & .522 & -.678 & .121 & -.861 & .241 \\
PEC3 & 2 & 5 & 4.32 & .675 & -.643 & .121 & -.061 & .241 \\
PES1 & 1 & 5 & 3.81 & .915 & -.596 & .121 & -.184 & .241 \\
PES2 & 1 & 5 & 3.59 & .975 & -.428 & .121 & -.454 & .241 \\
PES3 & 1 & 5 & 3.77 & .951 & -.709 & .121 & .289 & .241 \\
PEI1 & 1 & 5 & 3.57 & 1.004 & -.493 & .121 & -.292 & .241 \\
PEI2 & 1 & 5 & 3.68 & .864 & -.480 & .121 & -.041 & .241 \\
PEI3 & 1 & 5 & 3.60 & .936 & -.409 & .121 & -.107 & .241 \\
PEM1 & 2 & 5 & 4.40 & .736 & -1.207 & .121 & 1.293 & .241 \\
PEM2 & 2 & 5 & 4.34 & .709 & -.980 & .121 & .979 & .241 \\
PEM3 & 1 & 5 & 3.74 & 1.065 & -.712 & .121 & -.039 & .241 \\
Valid N (listwise) & & & & & & & \\
\hline
\end{tabular}

Notes: $\quad \mathrm{PE}=$ Psychological Empowerment, $\mathrm{PEC}=$ PE-Competency, $\quad \mathrm{PES}=$ PE-Self-Determination, PEI=PE-Impact, PEM=PE-Meaning

\subsubsection{Analysis for Common Method Bias}

The single factor variance (CMV) method was applied to test the common factor biases of this study as illustrated in Table 4. Previous studies have considered CMV as a limitation of these studies. The reason is that in self-reported questionnaires, there are chances of common factor biases (Laschinger, Grau, Finegan, \& Wilk, 2010; Rasli, 2006). Therefore, to ensure that the CMV does not have an effect on the data reliably and validity of this study, Harman's single factor method was used to control the effects of CMV. By the utilizing of SPSS, the method produced the overall variance of $25.911 \%$, as illustrated in Table 4 . This is less than the prescribed threshold of $50 \%$ and revealed the absence of common method bias of this study. 
Table 4. Common Factor Model CMV Analysis

\begin{tabular}{|c|c|c|c|c|c|c|}
\hline \multirow{2}{*}{ Component } & \multicolumn{3}{|c|}{ Initial Eigen values } & \multicolumn{3}{|c|}{ Extraction Sums of Squared Loadings } \\
\hline & Total & $\%$ of Variance & Cumulative \% & Total & $\%$ of Variance & Cumulative $\%$ \\
\hline 1 & 15.805 & 25.911 & 25.911 & 15.805 & 25.911 & 25.911 \\
\hline 2 & 8.298 & 13.603 & 39.514 & & & \\
\hline 3 & 2.500 & 4.098 & 43.611 & & & \\
\hline 4 & 2.193 & 3.595 & 47.206 & & & \\
\hline 5 & 1.685 & 2.762 & 49.969 & & & \\
\hline 6 & 1.586 & 2.601 & 52.569 & & & \\
\hline 7 & 1.529 & 2.506 & 55.075 & & & \\
\hline 8 & 1.276 & 2.092 & 57.167 & & & \\
\hline 9 & 1.138 & 1.866 & 59.032 & & & \\
\hline \multicolumn{7}{|c|}{ Extraction Method: Principal Component Analysis. } \\
\hline
\end{tabular}

\subsection{Measurement Model}

\subsubsection{Measurement Model of Psychological Empowerment}

For this study, CFA analyses for psychological empowerment was conducted to establish model fitness, construct validity, construct reliability, instrument validity and other associated analysis. It is essential for the researcher to confirm the unidimensionality, validity, and reliability for the all involved latent constructs prior of modeling their inter-relationship in a structural model (SEM) (Awang, 2014). However, the unidimensionality evaluation should be carried out first, before proceeding with the assessment of the validity and reliability (Awang, 2014; Khamis et al., 2014). Unidimensionality is achieved when the measuring items have presented acceptable factor loading (Khamis \& Kamarudin, 2014). According to Hair et al. (2010), factor loading is a fundamental building block in establishing instrument validity, especially convergent validity. A rule of thumb for CFA SEM analysis is that the standardized loading estimates should be 0.5 or higher, and ideally 0.7 or higher (Hair et al., 2010). Therefore, for this study, a coefficient of 0.50 and above was used as a minimum threshold value.

According to Awang (2014), construct validity is achieved when the Fitness Indexes for a construct achieve the required threshold. Although, in SEM, there are many Fitness Indexes indicate the degree of the fitness of the model to its respected data. There is no concurrence between scholars which fitness indexes to use. The recommendation is to use at least one fitness index from each category of model fit (Awang, 2014; Hair et al., 2010; Holmes-Smith et al., 2006). The researcher must report one incremental and one absolute index in addition to the Chi-square $(\chi 2)$ value and associated degrees of freedom, and at least one of these indices should be a badness-of-fit index (Calisir et al., 2013; Calisir et al., 2011; Hair et al., 2010; Liman et al., 2012; Peng, 2015)

The Psychological Empowerment (PE) construct is comprised of four subscales (dimensions) namely; Competency (PEC), Self-Determination (PES), Impact (PEI) and Meaning (PEM) (Spreitzer, 1995, 2008). The CFA analysis of PE and its subscales with related items was performed to determine its fitness for subsequent data analysis. Figure 2 represents the final Psychological Empowerment (PE) model after performing all the required adjustments.

Table 5. Standardized Regression Weights of Psychological Empowerment

\begin{tabular}{ccc}
\hline Relationship & Estimated FL Original & Estimated FL Modified \\
\hline PEC3<---F1 & .565 & .564 \\
PEC2<---F1 & .839 & .839 \\
PEC1<---F1 & .811 & .812 \\
PES3<---F2 & .707 & .708 \\
PES2<---F2 & .806 & .806 \\
PES1<---F2 & .790 & .789 \\
PEI3<---F3 & .808 & .807 \\
PEI2<---F3 & .904 & .905 \\
PEI1<---F3 & .727 & .727 \\
PEM3<---F4 & .490 & .596 \\
PEM2<---F4 & .873 & .757 \\
PEM1<---F4 & .818 & .946 \\
\hline
\end{tabular}

Notes: F1 = PE-Competency (PEC), F2=PE-Self dtermination (PES), F3=PE-Impact (PEI) \& F4=PE- Meaning (PEM) 


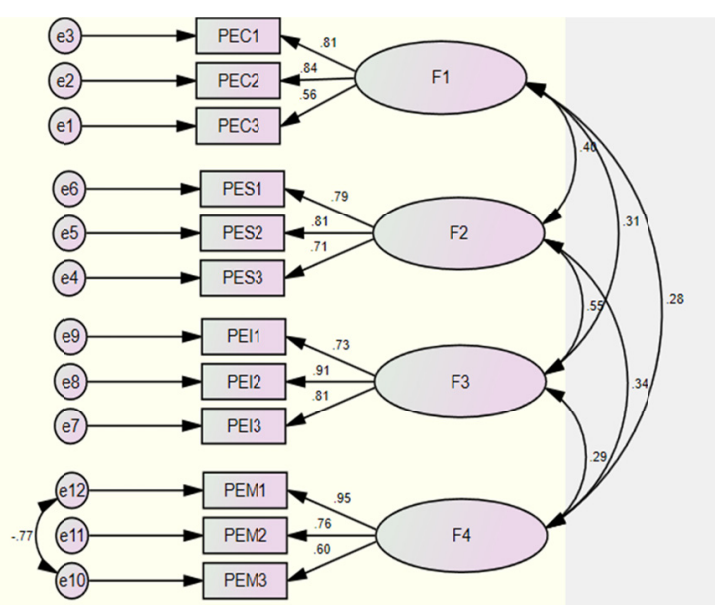

Notes: F1=PE-Competency (PEC),F2=PE-Self dtermination (PES), F3=PE-Impact (PEI) \& F4=PE-Meaning (PEM)

Figure 2. Measurement Model for Psychological Empowerment (PE)

The results of the CFA analysis of PE are displayed in Tables 5 and Table 6. The factor loading were all above (FL>.5) except for PEM3, which had a factor load of .490. Covariance between PEM1 and PEM3 was performed. This action improved model fit and also improved the PEM3 to .596 (Table 4.8). PEM3 with $\mathrm{FL}=.596$ gave the opportunity to maintain the rule of thumb of maintaining a minimum of three items per variable (PEM) as per Hair et al. (2010). The range of standardized regression weights of this model after the improvement was from .564 to .946 as in Table 5, while the improved fit indices are illustrated in Table 6 . The final CFA modified model yielded the improved values of the indices that are reflected in Table 6 . The value of these indices demonstrated that the PE model is fit for further SEM analysis.

Table 6. Fit Indces of Psychological Empowerment (PE).

\begin{tabular}{cccccccc}
\hline Index & CMIN & DF & CMIN/DF & CFI & TLI & NFI & RMSEA \\
\hline Reverence (Hair et al., 2015) & - & - & $<5$ & $>.900$ & $>.900$ & $>.900$ & $<.080$ \\
Model adjustments & & & & & & & \\
Default model-Original & 117.517 & 48 & 2.448 & .965 & .952 & .943 & .060 \\
After Covariance between PEM 1 and PEM 3 & 105.399 & 47 & 2.243 & .971 & .959 & .949 & .055 \\
\hline \multicolumn{3}{c}{ Model Fit Admissible } \\
\hline
\end{tabular}

\subsubsection{Composite /Construct Reliabilty of Measurement Model}

The results of the SPSS 21 analysis of the Cronbach's $\alpha$ for each subscale of this study are illustrated in Table 7. The results are above .70, the threshold value of the construct reliability (Blumberg, Cooper, \& Schindler, 2011; McMillan \& Schumacher, 2001; Rasli, 2006). The results were consistent with another method deployed for assessing the construct reliability for this study. The calculation of composite reliability for purpose of construct reliability and the construct convergent validity was accomplished by AMOS 18. As per the results, all composite reliabilities were within the acceptable value of .70 or above (Blumberg et al., 2011; Rasli, 2006). These results established the construct reliability and in addition some degree of convergent validly of these constructs.

Table 7. Represents Cronbach's Alpha Reliability and Composite Reliability of PE

\begin{tabular}{ccccc}
\hline \multicolumn{2}{c}{ Cronbach's Alpha $(\alpha)$} & \multicolumn{2}{c}{ Composite Reliably (CR) } \\
\hline Subscale & Number Items & Cronbach's Alpha $(\alpha)$ & Number of Items & Composite Reliably \\
\hline PEC & 3 & .753 & 3 & 0.790 \\
PES & 3 & .809 & 3 & 0.812 \\
PEI & 3 & .844 & 3 & 0.856 \\
PEM & 3 & .717 & 3 & 0.797 \\
\hline \multicolumn{2}{r}{ Original Items without any deletion-Original Model } & Items as per the adjusted model and items deletions \\
\hline
\end{tabular}

Notes: $\mathrm{PE}=$ Psychological Empowerment, PEC=PE-Competency, PES=PE-Self-Determination, PEI=PE-Impact, PEM=PE-Meaning.

\subsubsection{Convergent Validity}

Convergent validity of the construct is a reflection of the extent of the mutual proportion of variance between factors and it indicates the amount of correlation among the measures of the same concept (Hair et al., 2015). It 
is associated with construct loadings and their significance, with average the variance extracted (AVE), and construct reliabilities. The standard value AVE is higher than 0.5 , but a value of less than 0.5 is acceptable in condition that the composite reliability (CR) is higher than 0.6. In this condition the convergent validity of the construct is still adequate for SEM analyses (Fornell \& Larcker, 1981; Huang et al., 2013). In addition to the composite reliability (CR) and AVE of the construct, for the determination of the convergence validity, it vital to examine the significance of the factor loading into the construct. The factor loading (FL) is an indication of factors convergence into the latent construct, hence, it is a fundamental indication of convergence validity (Hair et al., 2010). Table 8 represents the regression weights of all the items that had been loaded significantly on the constructs at a P-value less than 0.05 , and the CR and AVE of the contracts. The condition is well established in this study as per the FL and P values. Thus, the convergence validity of this study can is established since it met the required criteria.

Table 8. Standardized Regression Weights, Composite Reliably and AVE of PE.

\begin{tabular}{cccccccc}
\hline Item & Relation & Construct & (FL) Estimate & P value & Label & Composite Reliability & AVE \\
\hline PEC3 & $<---$ & PEC & .593 & 0.000 & Significant & & 0.561 \\
PEC2 & $<---$ & PEC & .817 & 0.000 & Significant & 0.790 & 0.591 \\
PEC1 & $<---$ & PEC & .814 & 0.000 & Significant & & \\
PES3 & $<---$ & PES & .707 & 0.000 & Significant & & \\
PES2 & $<---$ & PES & .810 & 0.000 & Significant & 0.856 & 0.666 \\
PES1 & $<---$ & PES & .786 & 0.000 & Significant & & \\
PEI3 & $<---$ & PEI & .804 & 0.000 & Significant & & 0.575 \\
PEI2 & $<---$ & PEI & .912 & 0.000 & Significant & & \\
PEI1 & $<---$ & PEI & .722 & 0.000 & Significant & & 0.797 \\
PEM3 & $<---$ & PEM & .552 & 0.000 & Significant & & \\
PEM2 & $<---$ & PEM & .838 & 0.000 & Significant & & 0.57 \\
PEM1 & $<---$ & PEM & .848 & 0.000 & Significant & & \\
\hline
\end{tabular}

Notes: PE=Psychological Empowerment, $\mathrm{PEC}=$ PE-Competency, $\mathrm{PES}=$ PE-Self Determination, PEI=PE-Impact, PEM=PE-Meaning

\subsubsection{Descrimenent Validity}

Discriminant validity is the degree to which an instrument comprises a construct that is truly distinguished from the rest. It is also known as the extent to which correlated constructs have distinct values. There are many ways of calculating this type of validly, the two methods used for this study are the correlation approach based on Hair et al. (2010) and a chi-square difference test as per Segars (1997).

Correlation coefficients between measures of a construct and measures of conceptually different variables are usually given as evidence of discriminant validity (Chong, Nazim, \& Ahmad, 2014; Nazim \& Ahmad, 2013). According to Hair et al. (2010), if the correlations of two latent variables exceed 0.9, they have significant overlapping constructs. In the correlation method one of the criteria is stating that this validly is met when the correlation among exogenous constructs is less than or equal to 0.85 (Blumberg et al., 2011). However, in general in this method, the precise threshold level of the discriminant validity is debatable; after all, "when is a correlation close to one"? Some scholars suggest a threshold of 0.85 (Clark \& Watson, 1995; Henseler, Ringle, \& Sarstedt, 2015; Kline, 2011), while others propose a value of 0.90 (eg. Gold, Arvind Malhotra, \& Segars, 2001; Hair et al., 2010; Henseler et al., 2015; Teo, Srivastava, \& Jiang, 2008). Tables 9 represent the overall correlation among the variable. Clearly the values of correlation are below the prescribed thresholds' values of 0.90 (eg. Gold et al., 2001; Hair et al., 2010; Teo et al., 2008), thus, with this method, the discriminant validity is well established among the all subscales of this study.

Table 9. Correlation Values of the PE

\begin{tabular}{ccccc}
\hline \multicolumn{2}{l}{ Psychological Empowerment Correlations } & & & \\
\hline Subscale & PEC & PES & PEI & .216 \\
\hline PEC & 1 & .379 & .291 & .312 \\
PES & 379 & 1 & .500 & .281 \\
PEI & .291 & .500 & 1 & .281 \\
PEM & .216 & .312 & & 1 \\
\hline Notes: PE = Psychological Empowerment, & PEC $=$ PE-Competency, $P E S=$ PE-Self Determination, PEI=PE-Impact, \\
PEM=PE-Meaning WP=Work Performance. & & & \\
\hline
\end{tabular}


The Chi-square difference test of Segars (1997) is another method of assessing discriminant validity (Bertea \& Zait, 2011; Gefen, Straub, \& Boudreau, 2000). This method is accomplished by comparing two models, in one which the constructs are correlated, while in the other they are not. The significant results of the test represent the discriminant validity of the construct. This process is accomplished through the Confirmatory Factor Analysis (CFA). The requirement is to have a reflective measurement models which are introduced in pairs during the analysis (Bertea \& Zait, 2011; Segars, 1997). Accordingly, for this study, the first reflective model was analyzed through CFA where the constructs were not correlated, while the second model with correlated constructs. For each model, the value for the Chi-square and the degrees of freedom (df) was obtained. After that, the difference between the values of the two models was obtained. The results as presented in Table 10, revealed significant $p$ values $(p<.05)$, and thus, the discriminant validly of the presented model can be clearly established. This method provides supportive results of the correlation method that was previously presented.

Table 10. Chi-Square Difference Test Results of PE

\begin{tabular}{|c|c|c|c|c|c|c|c|}
\hline \multirow[b]{2}{*}{ Measurement Model } & \multicolumn{2}{|c|}{ Without Covariance } & \multicolumn{2}{|c|}{ After Covariance } & \multicolumn{3}{|c|}{ Results of the Test } \\
\hline & $\begin{array}{l}\text { Chi } \\
\text { Squire }\end{array}$ & $\begin{array}{c}\text { Degree of } \\
\text { Freedom (DF) }\end{array}$ & $\begin{array}{l}\text { Chi } \\
\text { Squire }\end{array}$ & DF & $\begin{array}{l}\text { Delta Chi } \\
\text { Squire }\end{array}$ & $\begin{array}{l}\text { Delta } \\
\text { DF }\end{array}$ & $\begin{array}{l}\mathrm{P} \text { Value. The result is } \\
\text { Significant at } \mathrm{P}<.05\end{array}$ \\
\hline $\begin{array}{c}\text { Psychological } \\
\text { Empowerment } \\
\text { (Construct) } \\
\text { PEC, PES, PEI \& } \\
\text { PEM }\end{array}$ & 105.399 & 47 & 313.667 & 54 & 208.268 & 7 & $\begin{array}{l}\text { P- value }=.00001 \\
\quad \text { (Significant) }\end{array}$ \\
\hline $\begin{array}{l}\text { P Value from Chi } \\
\text { Calculator }\end{array}$ & & http://www & statis & $\mathrm{m} / \mathrm{pv}$ & /chidis & lon.aspx & ated 11 October 2017 \\
\hline
\end{tabular}

Notes: $\mathrm{PE}=$ Psychological Empowerment, $\mathrm{PEC}=$ PE-Competency, $\mathrm{PES}=\mathrm{PE}-\mathrm{Self}$ Determination, PEI=PE-Impact, $\mathrm{PEM}=$ PE-Meaning WP=Work Performance.

\subsection{Descriptive Statistics of Psychological Empoerment (PE)}

Table 11 clearly represents the range, means, standard deviation, Skewness and kurtosis of the main variable and its related subscales, based on the 407 respondents who replied to the questionnaire. The mean and the standard deviation indicate the degree of existence or practice of these variables by the 407 respondents

To answer to research question which addresses the degree of which the OCSA heads of sections perceive their level of the overall psychological empowerment (PE) and its four subscales, means and standards deviations were used to achieve this objective. As illustrated in Table 11, the lowest mean of Spreitzer (1995)'s PE model is $\mathrm{M}=3.6175$ and the highest mean is $\mathrm{M}=4.5020$. The overall results indicated that the heads of sections have a high level of PE $(\mathrm{M}=4.0014)$. Talking about the means and standard deviations of the four dimensions of this PE model, the mean of competency (PEC) is higher than all other means $\mathrm{M}=4.502$ ), followed by meaning (PEM) with the mean of $\mathrm{M}=4.161$ ) and self-determination (PES) with a mean of $\mathrm{M}=3.7248$ respectively. Impact (PEI) has the lowest mean with values of $M=3.6175$. Further, the variability of scores is higher in PEM and PES than the rest of the two dimensions with standard deviation (SD) values of .817360 and .8058). The detailed results are displayed in Table 11.

Table 11. Means and Standard Deviation of Psychological Empowerment

\begin{tabular}{ccccc}
\hline N=407 & Minimum & Maximum & Mean & Std. Deviation \\
\hline Description & & & & .49837 \\
PE & 2.25 & 5.00 & 4.0014 & .47364 \\
PEC & 3.33 & 5.00 & 4.5020 & .80580 \\
PES & 1.00 & 5.00 & 3.7248 & .81736 \\
PEI & 1.00 & 5.00 & 3.6175 & .68081 \\
PEM & 1.67 & 5.00 & 4.1613 & PEI \\
\hline
\end{tabular}

Notes: PE=Psychological Empowerment, PEC=PE-Competency, PEI=PE-Self Determination, PEI=PE-Impact, PEM= PE-Meaning,

\section{Discussion}

The purpose of this section is to discuss the findings and conclusions derived from the utilization of the diversity tools and techniques of data analysis. It discusses the study findings that are based on the research questions and objectives, and it compares these results to other relevant research from the existing body of literature. Also it discusses the theoretical and practical contribution of this research to the area of social studies; specifically the 
practical implications in the Omani context. The recommendations for future studies and the limitations of this study are also presented in this section.

The objectives of this study is to investigate the degree to which OCSA employees are psychologically empowered and accordingly the main research question is what is the degree of perception of psychological empowerment (PE) and their dimensions by the OSCA heads of sections. Descriptive statistics will the means to reply to the main research question.

The overall results indicated that the heads of sections of OCSA have a high level of psychological empowerment (PE). Other studies conducted in the diversity areas of research in different contexts from the current study, revealed similar results (e.g., Ambad \& Bahron, 2012; Lee et al., 2016; Nestico, 2016; Neves \& Ribeiro, 2016; Raymer, 2014; Tung \& Tung, 2016). The high level of perception of OCSA heads of sections is an indication of their high feelings of competence, autonomy, meaning and impact of these employees towards their work. These four factors are independent and distinct from one another, yet there are interrelated and mutually reinforcing (Gagné et al., 1997; Meng et al., 2016; Spreitzer, 1995, 2008).

The results indicated that competence is the highest state of $\mathrm{PE}$ as perceived by the heads of sections. This high perception of competence, is an indication that the heads of section believe that they possess the required level of competence to perform their jobs successfully. Other studies also found competence to be the highest perceived dimension of PE (eg. Ambad \& Bahron, 2012; Boudrias, Gaudreau, Savoie, \& Morin, 2009; Çekmecelioglu \& Özbag, 2016; Joo \& Lim, 2013; Lana \& Chongb, 2015; Nestico, 2016; Neves \& Ribeiro, 2016). However, some studies have showed different results. For example Indradevi (2012) reported that self-determination, impact and meaning are perceived equally, while competence was perceived as a lower dimension of $\mathrm{PE}$ 。

Meaning is the second most perceived dimension of PE. It is an indication of the high level of the importance of work and it is also an indication that the work activities have a high personal meaning to the OCSA heads of sections. According to Araújo (2016), many scholars believe that meaning is the main driver of PE, and precisely, it is created as a result of meaning. Some studies also indicate that meaning as the second highest perceived dimension (e.g., Ambad \& Bahron, 2012; Çekmecelioglu \& Özbag, 2016; Joo \& Lim, 2013; Nestico, 2016). Nonetheless, other studies have showed that meaning is the highest perceived dimension of PE (e.g., Ginsburg et al., 2016; Indradevi, 2012; Neves \& Ribeiro, 2016).

Self-determination is the third dimensions of PE as perceived by the OSCA' heads of sections. This status of self-determination indicates that heads of sections possess the sense of autonomy or self-determination in a moderate to high level. It is a reflection of the individual's sense of having freedom or a personal preference for initiating and regulating of action related to work. With this degree of self-determination, heads of sections feel that they have significant autonomy in establishing the best ways of accomplish tasks, and have considerable independence and freedom in the methodology of executing the assigned work tasks. Other studies conducted in different contexts revealed similar results to this current study (e.g., Ambad \& Bahron, 2012; Çekmecelioglu \& Özbag, 2016; Ginsburg et al., 2016; Joo \& Lim, 2013; Neves \& Ribeiro, 2016).

Impact is the least subscale of psychological empowerment (PE) in this study. This finding is in line with other studies that were conducted in different contexts (e.g., Ambad et al., 2012; Boudrias et al., 2009; Çekmecelioglu \& Özbag, 2016; Ginsburg et al., 2016; Joo \& Lim, 2013; Neves \& Ribeiro, 2016). The results indicate that heads of sections perceive impact at moderate to high level. It reflects the degree to which heads of sections may influence strategic, administrative or operating work outcomes. This psychological status of employees creates a significant feeling of control, influence and impact on the events that occurring in work place.

The overall perception of the four dimensions of PE indicate that heads of sections of OCSA perceive themselves to have high levels of competence and their work is highly meaningful to them. In addition they have a considerable sense of independence and autonomy in relation to their work activity. Their feeling of impact, control or influence on the tasks or work related activities is less in comparison to the other three dimensions, yet it is considered to be high statistically.

Clearly, as mentioned by many previous studies, there is inconsistency in the degree of perception of the four dimensions of the PE by the individuals. However, the general finding is that competence and meaning are the two dimensions that are most highly perceived as indicated by many studies, while the two least perceived dimensions are self-destination and impact. Theoretically, the four cognitions, competence, meaning, self-determination and impact, collectively contribute to create the psychological empowerment of the individual (Spreitzer, 2008). However, as revealed by this study, and as compared to the previous studies' findings that, the levels of perception of PE by the employee are not equal. Thus, the degree of contribution and influencing of work outcomes such as work performance is also expected to vary. 
The degree of witch the overall psychological empowerment (PE) is perceived as well is its dimension is perceived by the employees vary from one context and another and may also vary from one sector to another. This variation could be attributed to role of PE antecedents and their degree of influence on the perception of this construct and its subscales by the employees. The role of leadership may have a great influence from one context more than other, or one type of leadership could have more impact in comparison to another type of leadership. This scenario could be also true on other antecedent of PE.

\subsection{Research Contribution}

This study's contribution as previously highlighted is sourced from the following important areas; conceptual/theoretical, and practical. Therefore, the findings of this research are also in accordance with these two areas. The subsequent two subsections presents this current study's contribution.

\subsubsection{Theoretical/Conceptual Implication.}

These theoretical contributions are highlighted in the subsequent paragraphs in this section. This study assessed the level of existence and the level of practice of the psychological empowerment in OCSA. The results of the descriptive statistics revealed that psychological empowerment (PE) with its subscales was highly perceived by the heads of section.

These results have important theoretical and practical implications for both the researchers and practitioners. For the academic, the results give a picture of the existence of the variables in this area of research. These statistics reflect the degree to which the variable is practiced or perceived by the sample population which is where the researcher or practitioner intersect. The academic expectation, for example that high perception of the PE may lead to employees with high work performance behaviors. For the practitioners, the results may be used to indicate the areas that require improvement and sustainably by establishing a continuing process of assessment, feedback, and training in their organizations.

This current study moreover has empirically test the variable of psychological empowerment (PE). The descriptive statistics revealed that the heads of section have a high perception of overall PE. At the dimension level, the results showed that the four dimensions of PE, are all perceived at a high level by the heads of section and all, as said, contribute to the overall perception of the PE. With this result, the study has proved empirically, in this study context, what was previously claimed by Spreitzer (1995), that the four dimensions are independent yet, collectively contribute to the overall perception of PE.

\subsubsection{Practical Implication to Knowledge}

One of the practical implications of this current study is that it provided a picture of the level of perception of psychological empowerment (PE) by the heads of section of OCSA. It is essential for the leadership of the OCSA to ensure that this type of empowerment is enhanced and maintained at a similar level of Social Structure Empowerment in order to maintain the overall sustainability of employees' empowerment, because of the vital role of PE in providing the autonomous motivation that is essential to drive organizational work performance behaviors. This recommendation, as explained earlier, will contribute to overcome one of the obstacles of the development and to maintain governmental performance in Oman as highlighted by the Minsitry of Civil Service (2012).

Practically, if employees appreciate that their outcome in behavioral performance has an impact on achieving the organizational goals and, in addition, that they psychologically empowered, that feeling of empowerment will grant them the sense of self-efficacy, self-determination (autonomy), a feeling of their having an impact on work outcomes and the sense of the high meaning of work, then these two combinations will ensure that the employees will align their effort to achieve the organizational goals. The role of leadership in aligning of these two areas is essential, and is what expected from the quality behaviors of the OCSA' leadership.

This study provides recommendations to the Ministry of Civil Services as a practical contribution to the National Plan for the Human Resources Development. The training and employee development plans should focus on employees' empowerment and particularly psychological empowerment (PE). Social structure empowerment is part of employees' terms of reference, but PE is a perception of empowerment within the employee and not part of their terms of reference. It is an intervening mechanism that provides the autonomous motivation that is essential for leadership to drive the performance behaviors. The Ministry of Civil Services may utilize this information to establish up the ground rules for the training for the OCSA employees.

\subsection{Limitation of the Study}

Numerous limitations may be present in this study, though the researcher put in a maximum effort to ensure the 
ultimate integrity of this present study. The literature review generally revealed that there is a scarcity of studies on psychological empowerment (PE) specifically in the public services organization. This current study's main focus is the study of the level of perception of PE only in the Omani Civil Services Agencies (OCSA). The generalizations must therefore be restricted to only the context of OCSA. To minimize this limitation, the next requirement is to conduct this research, in the civil services, security services of the public sectors and in addition, to extend this research to the wider and more diverse scope of the private sector. Another limitation is that this study covered only the OCSA heads of sections' perception of PE. Accordingly, the limitation of the generalization of the current study is heads of section level of PE and its dimension (competence, self-determination, meaning and impact). To overcome this limitation, and to have a better picture, this study should be conducted across different levels of the organizational hierarchy.

One of limitation of this study is the lack of transparency related to sensitive or confidential information associated with the participant agencies in the survey. The dissemination of this highly sensitive information to the researcher might be given by the participants with a low level of accuracy because of reluctance to divulge. To minimize the impact of this limitation, extra research, mainly qualitative research, should be conducted to compensate for any lack of data in this present study. The mixed method is a common approach in this type of research situation when the researcher demands more assurance on data accuracy (Todd, 1979).

\subsection{Recommendation of the Future Studies}

In order to further develop this present study, the future directions that may be followed in this specific area of research are highlighted by this study. To achieve this requirement, the following is suggested:

The results of the current study are limited to the scope of this study that covers an assessment of perception of psychological empowerment (PE) of OSCA heads of sections. All the assessments were only at the individual level and within the scope of the study only. They did not apply entire organization or the entire context of Oman. To have a better picture, this study shall be expanded to cover the entire hierarchy of the organization. Based on above, to better generalize for whole context of Oman, future studies must be expanded to cover other sectors of Omani government such as security agencies and all other organizations that do not follow the Ministry of Civil Services law. This expansion should also include the private sector such as oil and gas, banking, the hotel industry and others. Also the time horizon of the study should be expanded to a longitudinal empirical study that will give more solid research for the future direction. Future longitudinal and experimental studies that include for example; Oman Civil Services, military, security and private sectors would assist in confirming the causal paths investigated in the present study.

The current study covered analysis only at the individual level. Any the future study should expand the scope to the team and organizational level as follow up to Maynard et al. (2012). The expansion of the study from individual level to team and organizational level is vital for Oman since this region has few studies of this type. Thus, more studies are essential to expand knowledge in this research area.

The current study mainly examined PE and not social structure empowerment. The recommendation is to expand the study to include both types of empowerments. The purpose for this expansion is to develop a full empowerment model that comprises both types of empowerment, especially for this region which lacks empowerment studies. In fact the two types of empowerment complements each other and work side by side to produce overall empowered employees (Maynard et al., 2012; Seibert et al., 2011; Spreitzer, 2008). The recommendation for future studies is to develop a full model of work place empowerment specifically for OCSA, with the possibility of expanding the model to other sectors. This future recommendation is in line with studies conducted in the Asian and western context (e.g., Appelbaum et al., 2014; Appelbaum, Karasek, Lapointe, \& Quelch, 2015; Araújo, 2016; Neves \& Ribeiro, 2016; Pandey, 2016; Martin Morgan Tuuli et al., 2012).

The full comprehensive model of empowerment involves the organizational work environment and it is considered the foundation of the empowering process by associating the structure factors with the development of psychological conditions. This fully integrated empowerment model will have significant implication for knowledge in an area that is increasingly its popularity, especially in Oman, the context of the current study. It will include the macro level of empowerment presented by the social structure empowerment that is mainly associated with the organizational structure hierarchy and the micro level that is represented by PE and not stipulated in employees' terms of reference. According to Appelbaum et al. (2015), a comprehensive empowerment model would provide a better and in-depth understanding of empowerment and its defining factors and would also provide an excellent and vital tool for organizations wishing to implement empowerment in an optimal way, such as the OCSA.

This study did not included in its investigation the potential impact of the demographic data on the employees' 
on their psychological empowerment. For example, the assumption that age, work experience and educational level may have an influence on employee perception of PE. Therefore, future studies should investigate the influence of such demographic data on employees' perception of PE.

This study used quantitative methodology that focuses on collection and analysis of the numerical data associated with the studied variables of the phenomenon. The recommendation for the future studies is to utilize the mixed method approach that will allow the researchers to compare the quantitative method's findings with qualitative results to expand or validate the quantitative data (Creswell \& Clark, 2007). The mixed methods gives the researcher more confidence in results, stimulates the creation of innovative methods, and presents new approaches of capturing a problem to balance with conventional data-collection methods. In addition, it assists in uncovering the unexpected dimension of a phenomenon (Todd, 1979).

\section{Acknowledgments}

We are grateful to all those who made it possible for us to achieve this level of knowledge. We are grateful to all Omani Civil Service Agencies' employees who participated and invested their time in this study, many participated that we could not mention their names in these short lines, may Allah bless you all.

\section{References}

Al-Amri, B. (2013). The Impact of Employees Empowerment on the Level of their Performance as Percived by Department Heads in the Cental Ministries in Oman (Masters). AL Bayt University Un Published Thesis (1120505011)

Al-Araimi, M. F. (2012). The relationship between the full range of leadership styles and employees' creative performance in Civil Service organizations: A field study of Omani Civil Service managers. University of Manchester.

Al Zefeiti, S. M. B. (2017). The Influence of Transformational Leadership Behaviours on Oman Public Employees' Work Performance. Asian Social Science, 13(3), 102. doi: 10.5539/ass.v13n3p102

Al Zefeiti, S. M. B., \& Mohamad, N. A. (2015). Methodological Considerations in Studying Transformational Leadership and its Outcomes. International Journal of Engineering Business Management, 7. https://doi.org/10.5772/60429

ALKindy, A. M. Z. (2017). Transformational Leadership, Psychological Empowerment and Work Performance of Omani Civil Service Agencies (Doctor of Philosophy (Management) Resersch ), Universiti Teknologi Malaysia, Johor Bahru, Malaysis

Amabile, T. M. (1988). A model of creativity and innovation in organizations. Research in organizational behavior, 10(1), 123-167.

Ambad, S. N. A., \& Bahron, A. (2012). Psychological Empowerment: The Influence on Organizational Commitment Among Employees in the Construction Sector. The Journal of Global Business Management, $8(2), 73-81$.

Anderson, S. (2005). Collins English Dictionary. HarperCollins Glasgow.

Appelbaum, S. H., Karasek, R., Lapointe, F., \& Quelch, K. (2014). Employee empowerment: factors affecting the consequent success or failure-Part I. Industrial and Commercial Training, 46(7), 379. https://doi.org/10.1108/ICT-05-2013-0033

Appelbaum, S. H., Karasek, R., Lapointe, F., \& Quelch, K. (2015). Employee empowerment: factors affecting the consequent success or failure (Part II). Industrial and Commercial Training, 47(1), 23-30. http://dx.doi.org/10.1108/ICT-05-2013-0034

Araújo, J. P. M. (2016). Empowerment in SMEs: Two case-studies. (Master in Management), University of Porto.

Aryee, S., \& Chen, Z. X. (2006). Leader-member exchange in a Chinese context: Antecedents, the mediating role of psychological empowerment and outcomes. Journal of Business Research, 59(7), 793-801. https://doi.org/10.1016/j.jbusres.2005.03.003

Ashforth, B. E. (1989). The experience of powerlessness in organizations. Organizational Behavior and Human Decision Processes, 43(2), 207-242. https://doi.org/10.1016/0749-5978(89)90051-4

Ashforth, B. E. (1990). The organizationally induced helplessness syndrome: A preliminary model. Canadian Journal of Administrative Sciences/Revue Canadienne des Sciences de l'Administration, 7(3), 30-36. https://doi.org/10.1111/j.1936-4490.1990.tb00532.x 
Avolio, B. J., Zhu, W., Koh, W., \& Bhatia, P. (2004). Transformational leadership and organizational commitment: Mediating role of psychological empowerment and moderating role of structural distance. Journal of organizational behavior, 25(8), 951-968. https://doi.org/10.1002/job.283

Awang, Z. (2014). A handbook on SEM for academicians and practitioners: the step by step practical guides for the beginners. Salangor: Bandar Baru Bangi, MPWS Rich Resources.

Babbie, R. (2012). The Practice of Social Research. Cengage Learning.

Bandura, A. (1977). Self-efficacy: Toward a unifying theory of behavioral change. Psychological review, 84(2), 191. https://doi.org/10.1037/0033-295X.84.2.191

Bandura, A. (1982). Self-efficacy mechanism in human agency. American psychologist, $37(2), 122$. https://doi.org/10.1037/0003-066X.37.2.122

Bandura, A. (1986). Social foundations of thought and action: A social cognitive theory. Prentice-Hall, Inc.

Bandura, A. (1989). Human agency in social cognitive theory. American psychologist, 44(9), 1175. https://doi.org/10.1037/0003-066X.44.9.1175

Barlett, J. E., Kotrlik, J. W., \& Higgins, C. C. (2001). Organizational research: Determining appropriate sample size in survey research. Information technology, learning, and performance journal, 19(1), 43.

Bedi, G., Cooper, Z. D., \& Haney, M. (2013). Subjective, cognitive and cardiovascular dose-effect profile of nabilone and dronabinol in marijuana smokers. Addiction biology, 18(5), 872-881.

Bell, N. E., \& Staw, B. M. (1989). 11 People as sculptors versus sculpture: the roles of personality and personal control in organizations. Handbook of career theory, 232. https://doi.org/10.1111/j.1369-1600.2011.00427.x

Bentler, P. M. (1980). Multivariate analysis with latent variables: Causal modeling. Annual review of psychology, 31(1), 419-456.

Bertea, P., \& Zait, A. (2011). Methods for testing discriminant validity. Management \& Marketing-Craiova, (2), 217-224.

Blaschko, T., \& Burlingame, J. (2002). Assessment tools for recreational therapy and related fields (3rd ed.). Ravensdale, WA: Idyll Arbor Inc.

Blumberg, B., Cooper, D., \& Schindler, P. (2011). Business Research Methods. McGraw-Hill Education: Berkshire.

Bottaro, M. F., Heyward, V. H., Bezerra, R. F., \& Wagner, D. R. (2002). Skinfold method vs dual-energy x-ray absorptiometry to assess body composition in normal and obese women. J Exerc Physiol Online, 5(2), 11-18.

Boudrias, J.-S., Gaudreau, P., Savoie, A., \& Morin, A. J. (2009). Employee empowerment: From managerial practices to employees' behavioral empowerment. Leadership \& organization development journal, 30(7), 625-638. https://doi.org/10.1108/01437730910991646

Brislin, R. W. (1970). Back-translation for cross-cultural research. Journal of cross-cultural psychology, 1(3), 185-216. https://doi.org/10.1177/135910457000100301

Bryman, A., \& Bell, E. (2015). Business research methods. Oxford University Press.

Burns, R. P., \& Burns, R. (2008). Business Research Methods and Statistics Using SPSS. SAGE Publications.

Byrne, B. M. (2010). Structural equation modeling with AMOS: Basic concepts, applications, and programming (2nd ed.). New York: Routledge Taylor \& Francis Group.

Byrne, B. M. (2013). Structural equation modeling with AMOS: Basic concepts, applications, and programming. Routledge.

Calisir, F., Altin Gumussoy, C., \& Guzelsoy, E. (2013). Impacts of learning orientation on product innovation performance. The Learning Organization, 20(3), 176-194. https://doi.org/10.1108/09696471311328442

Calisir, F., Gumussoy, C. A., \& Iskin, I. (2011). Factors affecting intention to quit among IT professionals in Turkey. Personnel review, 40(4), 514-533. https://doi.org/10.1108/00483481111133363

Carless, S. A. (2004). Does psychological empowerment mediate the relationship between psychological climate and job satisfaction? Journal of Business and Psychology, 18(4), 405-425. https://doi.org/10.1023/B:JOBU.0000028444.77080.c5 
Çekmecelioglu, H. G., \& Özbag, G. K. (2016). Psychological empowerment and support for innovation in Turkish manufacturing industry: Relations with individual creativity and firm innovativeness. Journal for East European Management Studies, 21(1), 10. https://doi.org/10.5771/0949-6181-2016-1-10

Chase, D. R., \& Godbey, G. C. (1983). The accuracy of self-reported participation rates. Leisure Studies, 2(2), 231-235.

Chase, D. R., \& Harada, M. (1984). Response error in self-reported recreation participation. Journal of Leisure Research, 16(4), 322. https://doi.org/10.1080/00222216.1984.11969603

Chebat, J.-C., \& Kollias, P. (2000). The impact of empowerment on customer contact employees' roles in service organizations. Journal of Service research, 3(1), 66-81. https://doi.org/10.1177/109467050031005

Chen, G., Kirkman, B. L., Kanfer, R., Allen, D., \& Rosen, B. (2007). A multilevel study of leadership, empowerment, and performance in teams. Journal of applied psychology, 92(2), 331. https://doi.org/10.1037/0021-9010.92.2.331

Chen, G., \& Klimoski, R. J. (2003). The impact of expectations on newcomer performance in teams as mediated by work characteristics, social exchanges, and empowerment. Academy of management journal, 46(5), 591-607.

Chong, E. E., Nazim, A., \& Ahmad, S. B. (2014). A comparison between individual confirmatory factor analysis and pooled confirmatory factor analysis: An analysis of library service quality, a case study at a public university in Terengganu. International Journal of Engineering Science and Innovative Technology, 3(1), 110-116.

Clark, L. A., \& Watson, D. (1995). Constructing validity: Basic issues in objective scale development. Psychological assessment, 7(3), 309. https://doi.org/10.1037/1040-3590.7.3.309

Common, R. K. (2011). Barriers to developing 'leadership'in the Sultanate of Oman. International Journal of Leadership Studies, 6(2), 215-228.

Conger, J. A., \& Kanungo, R. N. (1988). The empowerment process: Integrating theory and practice. Academy of management review, 13(3), 471-482.

Cotton, J. L. (1993). Employee involvement: Methods for improving performance and work attitudes. Sage Publications, Inc.

Cousineau, D., \& Chartier, S. (2015). Outliers detection and treatment: A review. International Journal of Psychological Research, 3(1), 58-67. https://doi.org/10.21500/20112084.844

Creswell, J. W. (2013). Research design: Qualitative, quantitative, and mixed methods approaches. Sage publications.

Creswell, J. W., \& Clark, V. L. P. (2007). Designing and conducting mixed methods research. Thousand Oaks CA: Sage.

Deci, E. L. (1975). Intrinsic motivation. New York and London: Plenum Press.

Deci, E. L., Connell, J. P., \& Ryan, R. M. (1989). Self-determination in a work organization. Journal of applied psychology, 74(4), 580. https://doi.org/10.1037/0021-9010.74.4.580

Deci, E. L., \& Ryan, R. M. (1987). The support of autonomy and the control of behavior. Journal of personality and social psychology, 53(6), 1024. https://doi.org/10.1037/0022-3514.53.6.1024

Den Hartog, H., Derix, M., Van Bemmel, A., Kremer, B., \& Jolles, J. (2003). Cognitive functioning in young and middle-aged unmedicated out-patients with major depression: testing the effort and cognitive speed hypotheses. Psychological medicine, 33(8), 1443-1451. https://doi.org/10.1017/S003329170300833X

Dorfman, P. W., \& House, R. J. (2004). Cultural influences on organizational leadership: Literature review, theoretical rationale, and GLOBE project goals. Culture, leadership, and organizations: The GLOBE study of, 62, 51-73.

Ennis, M. C. (2013). An investigation of the relationship between leadership practices and individualism-collectivism on withdrawal cognations/turnover intentions for local government employees on the Eastern Shore of Maryland: The role of organizational commitment. University of Maryland Eastern Shore

Ergeneli, A., Gohar, R., \& Temirbekova, Z. (2007). Transformational leadership: Its relationship to culture value dimensions. International Journal of Intercultural Relations, 31(6), 703-724. 
https://doi.org/10.1016/j.ijintrel.2007.07.003

Eylon, D., \& Bamberger, P. (2000). Empowerment Cognitions and Empowerment Acts Recognizing the Importance of Gender. Group \& Organization Management, 25(4), 354-372. https://doi.org/10.1177/1059601100254003

Forrester, R. (2000). Empowerment: Rejuvenating a potent idea. The Academy of Management Executive, 14(3), 67-80.

Frankfort-Nachmias, C., \& Nachmias, D. (2008). Research Methods in the Social Sciences (7th ed.). New Yeork: Worth Publishers.

Fuller, J. B., Morrison, R., Jones, L., Bridger, D., \& Brown, V. (1999). The effects of psychological empowerment on transformational leadership and job satisfaction. The Journal of Social Psychology, 139(3), 389-391. https://doi.org/10.1080/00224549909598396

Gagné, M., Senecal, C. B., \& Koestner, R. (1997). Proximal job characteristics, feelings of empowerment, and intrinsic motivation: A multidimensional model. Journal of applied social psychology, 27(14), 1222-1240. https://doi.org/10.1111/j.1559-1816.1997.tb01803.x

Gecas, V. (1989). The social psychology of self-efficacy. Annual review of sociology, 291-316. https://doi.org/10.1146/annurev.so.15.080189.001451

Gefen, D., Straub, D., \& Boudreau, M.-C. (2000). Structural equation modeling and regression: Guidelines for research practice. Communications of the association for information systems, 4(1), 7.

George, D., \& Mallery, P. (2006). SPSS for Windows step by step.

Gill, J., \& Johnson, P. (2010). Research methods for managers. Sage.

Ginsburg, L., Berta, W., Baumbusch, J., Dass, A. R., Laporte, A., Reid, R. C., . . Taylor, D. (2016). Measuring Work Engagement, Psychological Empowerment, and Organizational Citizenship Behavior Among Health Care Aides. The Gerontologist, gnv129. https://doi.org/10.1093/geront/gnv129

Gist, M. E. (1987). Self-efficacy: Implications for organizational behavior and human resource management. Academy of management review, 12(3), 472-485. https://doi.org/10.5465/amr.1987.4306562

Givens, R. J. (2011). The role of psychological empowerment and value congruence in mediating the impact of transformational leadership on follower commitment in American churches. International Journal of Leadership Studies, 6(2), 188-214.

Gold, A. H., Arvind Malhotra, \& Segars, A. H. (2001). Knowledge management: An organizational capabilities perspective. Journal of management information systems, 18(1), 185-214. https://doi.org/10.1080/07421222.2001.11045669

Hackman, J. R., \& Oldham, G. R. (1976). Motivation through the design of work: Test of a theory. Organizational behavior and human performance, 16(2), 250-279. https://doi.org/10.1016/0030-5073(76)90016-7

Hackman, J. R., \& Oldham, G. R. (1980). Work redesign.

Hair, J. F., Black, W. C., Babin, B. J., \& Anderson, R. E. (2010). Multivariate Data Analysis (7th ed.): Prentice Hall.

Hair, J. F., Celsi, M. W., Money, A. H., Samouel, P., \& Page, M. J. (2015). Essentials of Business Research Methods. Taylor \& Francis Group.

Henseler, J., Ringle, C. M., \& Sarstedt, M. (2015). A new criterion for assessing discriminant validity in variance-based structural equation modeling. Journal of the academy of marketing science, 43(1), 115-135. https://doi.org/10.1007/s11747-014-0403-8

Hezarvand, E. M. (2013). An investigation of job satisfaction organizational commitment and turnover intention in Iranian insurance industry. Universiti Teknologi Malaysia, Faculty of Management.

Highman, A. (1955). The Audited Self-Administered Questionnaire. Journal of Marketing, 20(2), 155-159. https://doi.org/10.2307/1247288

Hill, N. S., Kang, J. H., \& Seo, M.-G. (2014). The interactive effect of leader-member exchange and electronic communication on employee psychological empowerment and work outcomes. The Leadership Quarterly, 25(4), 772-783. 
Holmes-Smith, P., Coote, L., \& Cunningham, E. (2006). Structural equation modeling: From the fundamentals to advanced topics. SREAMS, Melbourne.

Indradevi, R. (2012). The impact of psychological empowerment on job performance and job satisfaction in Indian software companies. International Journal of Multidisciplinary Management Studies, 2(4), 45.

Joo, B.-K., \& Lim, T. (2013). Transformational leadership and career satisfaction: the mediating role of psychological empowerment. Journal of Leadership \& Organizational Studies. https://doi.org/10.1177/1548051813484359

Kanter, R. M. (1977). Men and Women of the Corporation. Basic Books.

Kanter, R. M. (1983). The change nmsters. New York: Simon \& Schuster, Inc.

Kark, R., Shamir, B., \& Chen, G. (2003). The two faces of transformational leadership: Empowerment and dependency. Journal of applied psychology, 88(2), 246. https://doi.org/10.1037/0021-9010.88.2.246

Khamis, A., \& Kamarudin, N. K. K. B. (2014). Measuring Job Satisfaction among Lecturers in Public University Using Structural Equation Model. Asian Journal of Science and Technology, 5(11), 705-712.

Khan, H. U. (2006). Role of Computer Mediated Communication in solving collaborative learning empowerment problems in higher education: a case study of Oman. Innovation in Teaching and Learning in Information and Computer Sciences, 5(4), 1-16. https://doi.org/10.11120/ital.2006.05040021

Klenke, K. (2008). Qualitative research in the study of leadership. Emerald group publishing.

Kline, R. (2010). Principles and practice of structural equation modeling (3rd ed.). New York: Guilford Press.

Kline, R. (2011). Principles and Practice of Structural Equation Modeling (3rd ed.). New York: Guilford Press.

Koberg, C. S., Boss, R. W., Senjem, J. C., \& Goodman, E. A. (1999). Antecedents and outcomes of empowerment empirical evidence from the health care industry. Group \& Organization Management, 24(1), 71-91. https://doi.org/10.1177/1059601199241005

Kraimer, M. L., Seibert, S. E., \& Liden, R. C. (1999). Psychological empowerment as a multidimensional construct: A test of construct validity. Educational and Psychological measurement, 59(1), 127-142. https://doi.org/10.1177/0013164499591009

Krejcie, R. V., \& Morgan, D. W. (1970). Determining sample size for research activities. Educ Psychol Meas. https://doi.org/10.1177/001316447003000308

Lana, X. M., \& Chongb, W. Y. (2015). The Mediating Role of Psychological Empowerment between Transformational Leadership and Employee Work Attitudes.

Lange, P., \& Steck, T. (2014). Near Field Communication-Its adoption process and technology acceptance.

Laschinger, H. K. S., Finegan, J., \& Shamian, J. (2001). The impact of workplace empowerment, organizational trust on staff nurses' work satisfaction and organizational commitment. Health care management review, 26(3), 7-23. https://doi.org/10.1097/00004010-200107000-00002

Laschinger, H. K. S., Grau, A. L., Finegan, J., \& Wilk, P. (2010). New graduate nurses' experiences of bullying $\begin{array}{lllll}\text { and burnout in hospital settings. } J \text { Adv } & \text { Nurs, } & 66(12), & 2732-2742 .\end{array}$ https://doi.org/10.1111/j.1365-2648.2010.05420.x

Lawler, E. E., Mohrman, S. A., \& Benson, G. (2001). Organizing for high performance: Employee Involvement, TQM, Reengineering, and Knowledge Management in the Fortune 1000. San Francisco: Jossey-Bass.

Leach, D. J., Wall, T. D., \& Jackson, P. R. (2003). The effect of empowerment on job knowledge: An empirical test involving operators of complex technology. Journal of Occupational and Organizational Psychology, 76(1), 27-52. https://doi.org/10.1348/096317903321208871

Lee, H., Jeon, S., \& Zeelim-Hovav, A. (2016). Impact of Psychological Empowerment, Position and Awareness of Audit on Information Security Policy Compliance Intention.

Lekander, M., Von Essen, J., Schultzberg, M., Andreasson, A. N., Garlind, A., HANSSON, L. O., \& NILSSON, L. G. (2011). Cytokines and memory across the mature life span of women. Scandinavian journal of psychology, 52(3), 229-235. https://doi.org/10.1111/j.1467-9450.2010.00865.x

Li, C., Zhao, H., \& Begley, T. M. (2015). Transformational leadership dimensions and employee creativity in China: A cross-level analysis. Journal of Business Research. https://doi.org/10.1016/j.jbusres.2014.11.009

Liden, R. C., \& Arad, S. (1996). A power perspective of empowerment and work groups: Implications for human 
resources management research. Research in personnel and human resources management, 14, $205-252$.

Liden, R. C., Sparrowe, R. T., \& Wayne, S. J. (1997). Leader-member exchange theory: The past and potential for the future. Research in personnel and human resources management, 15, 47-120.

Liden, R. C., \& Tewksbury, T. W. (1995). Empowerment and work teams. Handbook of human resources management, 386, 403.

Liden, R. C., Wayne, S. J., \& Sparrowe, R. T. (2000). An examination of the mediating role of psychological empowerment on the relations between the job, interpersonal relationships, and work outcomes. Journal of applied psychology, 85(3), 407. https://doi.org/10.1037/0021-9010.85.3.407

Liman, M. A., Ibrahim, M. B., \& Othman, J. (2012). Unveiling the values inculcation model among Mathematics teachers in developing country: A conceptual approach. IOSR Journal Of Humanities And Social Science, 5(1), 6-19. https://doi.org/10.9790/0837-0510619

Little, R. J. A., \& Rubin, D. B. (2014). Statistical Analysis with Missing Data. Wiley.

Locke, E. A., Frederick, E., Lee, C., \& Bobko, P. (1984). Effect of self-efficacy, goals, and task strategies on task performance. Journal of applied psychology, 69(2), 241. https://doi.org/10.1037/0021-9010.69.2.241

Maynard, M. T., Gilson, L. L., \& Mathieu, J. E. (2012). Empowerment-fad or fab? A multilevel review of the past two decades of research. Journal of Management, 38(4), 1231-1281. https://doi.org/10.1177/0149206312438773

McMillan, J. H., \& Schumacher, S. (2001). Research in education: A conceptual introduction. New York: Longman.

Meng, L., Jin, Y., \& Guo, J. (2016). Mediating and/or moderating roles of psychological empowerment. Applied Nursing Research, 30, 104-110. https://doi.org/10.1016/j.apnr.2015.11.010

Menon, S. (2001). Employee empowerment: An integrative psychological approach. Applied Psychology, 50(1), 153-180. https://doi.org/10.1111/1464-0597.00052

Ministry of Civil Service. (2015). The Annual Statistics of Civil Service Employees 2014 (p. 121). Muscat, Oman Directorate of General of Information and Statistics.

Minsitry of Civil Service. (2012). Recommendations of the Smposium of the Mechanism of Dvelopment of Government Performance. Muscat, Oman Minstry of Civil Services, Oman. Retrieved from http://www.mocs.gov.om/tabid/533/Default.aspx

Moye, M. J., Henkin, A. B., \& Egley, R. J. (2005). Teacher-principal relationships: Exploring linkages between empowerment and interpersonal trust. Journal of Educational Administration, 43(3), $260-277$. https://doi.org/10.1108/09578230510594796

Nazim, A., \& Ahmad, S. (2013). Assessing the unidimensionality, reliability, validity and fitness of influential factors of 8th grade student's mathematics achievement in Malaysia. Internafional Journal of Advance Research, 1(2), 1-7.

Nestico, C. (2016). Psychological Empowerment and Customer Orientation in the Grocery Industry. (D.B.A), Walden Univesity

Neves, N., \& Ribeiro, O. (2016). Perception of nurses' Empowerment in healthcare organization settings. Millenium-Journal of Education, Technologies, and Health, (1), 179-190. https://doi.org/10.29352/mill0201.14.00093

Nunnally, J., \& Bernstein, I. (1994). Psychometric theory (3rd ed.). McGraw-Hill. New York, NY.

O'Toole, J., \& Lawler, E. E. (2006). The New American Workplace. St. Martin's Press.

Ozer, E. M., \& Bandura, A. (1990). Mechanisms governing empowerment effects: a self-efficacy analysis. Journal of personality and social psychology, 58(3), 472. https://doi.org/10.1037/0022-3514.58.3.472

Pandey, J. (2016). Structural \& psychological empowerment in rural India. Indian Journal of Industrial Relations, 51(4), 579-594.

Patten, M. L. (2012). Understanding research methods (8th ed.). Glendale, CA: Pyrczak.

Peng, L. S., \& Moghavvemi, S. (2015). The Dimension of Service Quality and Its Impact on Customer Satisfaction, Trust, and Loyalty: A Case of Malaysian Banks. Asian Journal of Business and Accounting, $8(2), 32$. 
Phillips, D. L., \& Clancy, K. J. (1972). Some effects of "social desirability" in survey studies. American Journal of Sociology, 77(5), 921-940. https://doi.org/10.1086/225231

Rasli, A. (2006). Data Analysis and Interpretation-A Handbook for Postgraduate Social Scientists (+ CD). Penerbit UTM.

Raymer, S. D. (2014). The combined effects of leadership style and organizational culture type on psychological empowerment and organizational commitment. Colorado State University. Libraries.

Redmond, M. R., Mumford, M. D., \& Teach, R. (1993). Putting creativity to work: Effects of leader behavior on subordinate creativity. Organizational Behavior and Human Decision Processes, 55(1), 120-151. https://doi.org/10.1006/obhd.1993.1027

Rossiter, J. R. (2008). Content validity of measures of abstract constructs in management and organizational research. British Journal of Management, 19(4), 380-388. https://doi.org/10.1111/j.1467-8551.2008.00587.x

Rovai, A. P., Baker, J. D., \& Ponton, M. K. (2013). Social Science Research Design and Statistics: A Practitioner's Guide to Research Methods and IBM SPSS. Watertree Press.

Rubin, A., \& Babbie, R. (2010). Research Methods for Social Work. Cengage Learning.

Rumsey, D. J. (2016). Statistics For Dummies (2nd ed.). Wiley.

Saleh, M. A. (2006). Antecedents of commitment to an import supplier. Queensland University of Techology Brisbane.

Saunders, M., Lewis, P., \& Thornhill, A. (2012). Research Methods for Business Students (6th ed.). Pearson.

Saunders, M., Lewis, P., \& Thornhill, A. (2015). Research Methods for Business Students. Pearson Education Limited.

Segars, A. H. (1997). Assessing the unidimensionality of measurement: A paradigm and illustration within the context of information systems research. Omega, 25(1), 107-121. https://doi.org/10.1016/S0305-0483(96)00051-5

Seibert, S. E., Silver, S. R., \& Randolph, W. A. (2004). Taking empowerment to the next level: A multiple-level model of empowerment, performance, and satisfaction. Academy of management journal, 47(3), 332-349. https://doi.org/10.5465/20159585

Seibert, S. E., Wang, G., \& Courtright, S. H. (2011). Antecedents and consequences of psychological and team empowerment in organizations: A meta-analytic review. Journal of applied psychology, 96(5), 981. https://doi.org/10.1037/a0022676

Sekaran, U. (2003). Research Methods for Business. New York: John Milley and Sons. Inc. Semarang: Badan Penerbit Universitas Diponegoro.

Sekaran, U., \& Bougie, R. (2010). Research Methods for Business: A Skill Building Approach. John Wiley \& Sons.

Seo, S. (2006). A review and comparison of methods for detecting outliers in univariate data sets. University of Pittsburgh.

Shah, T. A., \& Nisar, M. (2011). Influence of transformational leadership on employees outcomes: Mediating role of empowerment. African Journal of Business Management, 5(21), 8558. https://doi.org/10.5897/AJBM11.1022

Simon, M. K., \& Goes, J. (2012). Disseration and Scholarly Research: Recipes for Success (2012 ed.). Seattle, WA Dissertation Success LLC.

Sparrowe, R. T. (1994). Empowerment in the hospitality industry: An exploration of antecedents and outcomes. Journal of Hospitality \& Tourism Research, 17(3), 51-73. https://doi.org/10.1177\%2F109634809401700306

Spreitzer, G. M. (1995). Psychological empowerment in the workplace: Dimensions, measurement, and validation. Academy of management journal, 38(5), 1442-1465. https://doi.org/10.5465/256865

Spreitzer, G. M. (1996). Social structural characteristics of psychological empowerment. Academy of management journal, 39(2), 483-504. https://doi.org/10.5465/256789

Spreitzer, G. M. (1997). Toward a common ground in defining empowerment. Paper presented at the National Academy of Management Meetings, 1995, Vancouver, BC, Canada; An earlier version was presented at the aforementioned conference. 
Spreitzer, G. M. (2008). Taking stock: A review of more than twenty years of research on empowerment at work. Handbook of organizational behavior, 54-72.

Spreitzer, G. M., Kizilos, M. A., \& Nason, S. W. (1997). A dimensional analysis of the relationship between psychological empowerment and effectiveness satisfaction, and strain. Journal of Management, 23(5), 679-704. https://doi.org/10.1177\%2F014920639702300504

Srivastava, U. R., \& Singh, M. (2008). Psychological Empowerment at Work Place. Global Journal of Business Management, 2(1), 53-69.

Tabachnick, B., \& Fidell, L. (2007). Using Multivariate Statistics (5th ed.). Boston Massachusetts: Pearson Education.

Tabachnick, B. G., \& Fidell, L. S. (1996). Using Multivariate Statistics. New York: HarperCollins College Publishers.

Tabachnick, B. G., Fidell, L. S., \& Osterlind, S. J. (2001). Using multivariate statistics.

Teo, T. S., Srivastava, S. C., \& Jiang, L. (2008). Trust and electronic government success: An empirical study. Journal of management information systems, 25(3), 99-132. https://doi.org/10.2753/MIS0742-1222250303

Thomas, K. W., \& Velthouse, B. A. (1990). Cognitive elements of empowerment: An "interpretive" model of intrinsic task motivation. Academy of management review, 15(4), 666-681. https://doi.org/10.5465/amr.1990.4310926

Todd, J. D. (1979). Mixing qualitative and quantitative methods: Triangulation in action. Administrative Science Quarterly, 24(2), 602-611.

Tsai, A. C., Scott, J. A., Hung, K. J., Zhu, J. Q., Matthews, L. T., Psaros, C., \& Tomlinson, M. (2013). Reliability and validity of instruments for assessing perinatal depression in African settings: Systematic review and meta-analysis. https://doi.org/10.1371/journal.pone.0082521

Tung, F.-C., \& Tung, F.-C. (2016). Does transformational, ambidextrous, transactional leadership promote employee creativity? Mediating effects of empowerment and promotion focus. International Journal of Manpower, 37(8), 1250-1263. https://doi.org/10.1108/IJM-09-2014-0177

Tuuli, M. M., \& Rowlinson, S. (2009). Performance consequences of psychological empowerment. Journal of construction engineering and management. https://doi.org/10.1061/(ASCE)CO.1943-7862.0000103

Tuuli, M. M., Rowlinson, S., Fellows, R., \& Liu, A. M. (2012). Empowering the project team: impact of leadership style and team context. Team Performance Management: An International Journal, 18(3/4), 149-175. https://doi.org/10.1108/13527591211241006

Ullman, J. B., \& Bentler, P. M. (2003). Structural equation modeling. Wiley Online Library.

Wagner, J. A. (1994). Participation's effects on performance and satisfaction: A reconsideration of research evidence. Academy of management review, 19(2), 312-330. https://doi.org/10.5465/amr.1994.9410210753

Wagner, J. A. (1995). On beating dead horses, reconsidering reconsiderations, and ending disputes: Further thoughts about a recent study of research on participation. JSTOR.

Wallach, V. A., \& Mueller, C. W. (2006). Job characteristics and organizational predictors of psychological empowerment among paraprofessionals within human service organizations: An exploratory study. Administration in Social Work, 30(1), 95-115. https://doi.org/10.1300/J147v30n01_06

Wat, D., \& Shaffer, M. A. (2005). Equity and relationship quality influences on organizational citizenship behaviors: The mediating role of trust in the supervisor and empowerment. Personnel review, 34(4), 406-422. https://doi.org/10.1108/00483480510599752

Woodman, R. W., Sawyer, J. E., \& Griffin, R. W. (1993). Toward a theory of organizational creativity. Academy of management review, 18(2), 293-321. https://doi.org/10.5465/amr.1993.3997517

Wyner, G. A. (1980). Response errors in self-reported number of arrests. Sociological Methods \& Research, 9(2), 161-177. https://doi.org/10.1177/004912418000900203

Yang, B. (2005). Factor analysis methods. In R. A. Swanson, \& E. F. Holten III (Eds.), Research in organizations: Foundations and methods of inquiry (3rd ed.). San Francisco, CA: Berrett-Koehle. 


\section{Appendix A: Coparson between SSC and PE.}

Table A1.

Table: - Comparison between Social Structure Empowerment (SSE) and Psychological Empowerment (PE) Assessment Questionnaires

\begin{tabular}{|c|c|c|c|}
\hline $\begin{array}{l}\text { SSE Dimension } \\
\text { (Lasehiager et al, } \\
\text { 2001) }\end{array}$ & $\begin{array}{l}\text { Example of Questions } \\
\text { Adapted (Lautixi ot al, 2009) }\end{array}$ & $\begin{array}{l}\text { PE Dimention } \\
\text { (Spreitzer } \\
1995 \text { ) }\end{array}$ & $\begin{array}{l}\text { Meaturing Item: } \\
\text { (Spreitzer 1995) }\end{array}$ \\
\hline \multirow[t]{3}{*}{ Opportunity } & 1 bave a chance of Challenging work & \multirow[t]{3}{*}{ Meaning } & The work $I$ do is very important to me \\
\hline & I bave the chance to gain bew akilla and knowledge on the job & & The work I do is meaningful to me \\
\hline & $\begin{array}{l}\text { I bave the chance to do tasks and use all of my own skalls and } \\
\text { knowiled re }\end{array}$ & & My job activities are personslly mesningful to me \\
\hline \multirow[t]{3}{*}{ Information } & I bave the Information on the current state of the boapital & \multirow[t]{3}{*}{ Competency } & I am confident about my ability to do my job \\
\hline & I bave the information on the values of top management & & $\begin{array}{l}\text { I am self-assured about ny eapabilities to pesform my work } \\
\text { activities }\end{array}$ \\
\hline & I bave the information on the goals of top management & & I have mastered the aklli necesaary for my job \\
\hline \multirow[t]{3}{*}{ Support } & $\begin{array}{l}\text { I bave the support and acknowledgement specifically on things } \\
\text { that I do well }\end{array}$ & \multirow[t]{3}{*}{$\begin{array}{l}\text { Self } \\
\text { Determination }\end{array}$} & $\begin{array}{l}\text { I bvve a great deal of cootrol over what happens in my } \\
\text { department }\end{array}$ \\
\hline & $\begin{array}{l}\text { I receive comments specifically about things that } 1 \text { could } \\
\text { improve }\end{array}$ & & $\begin{array}{l}\text { I bave significant influence over what bappens in my } \\
\text { depatment }\end{array}$ \\
\hline & I receive belpfal hints or problem solving advice & & My impact on what bappens in my department is larze \\
\hline \multirow[t]{3}{*}{ Reteuret } & I bave enough time to do necessary paperwork & \multirow[t]{9}{*}{ Impact } & \multirow{2}{*}{$\begin{array}{l}\text { I have a great deal of control over what happens in my } \\
\text { department } \\
\text { I have significant infuence over what happens in my } \\
\text { department }\end{array}$} \\
\hline & I have enough time to aceomplish the requirements of the job & & \\
\hline & I can acquire temporary belp when needed & & \multirow[t]{7}{*}{ My impact on what bappens in my departuent is large } \\
\hline \multirow[t]{3}{*}{ Formal Power } & I receive rewarda for the innovation on my job & & \\
\hline & I bave the required amount of Rexablity is my job & & \\
\hline & $\begin{array}{l}\text { I have the required amount of visibilaty of my work-telated } \\
\text { issue }\end{array}$ & & \\
\hline \multirow[t]{3}{*}{ Informal Power } & I bave the collaboration on papient care with phyacians & & \\
\hline & I have being sought out by peets for belp with problems & & \\
\hline & $\begin{array}{l}\text { I may Seek out idess from professionsls other thrn physicisns, } \\
\text { e.g. phyziotherapiats, occupational therapiata, dieticians }\end{array}$ & & \\
\hline
\end{tabular}

Table A2.

Table: General Comparison between Social Structure Empowerment (SSE) and Psychological Empowerment (PE)

\begin{tabular}{|c|c|c|}
\hline \multirow[b]{2}{*}{$\begin{array}{l}\text { Studies that derived } \\
\text { empowrerment } \\
\text { And Theoretical } \\
\text { Perspective }\end{array}$} & Social Structure Empowerment (SSE) & Psychological Empowerment (PE) \\
\hline & 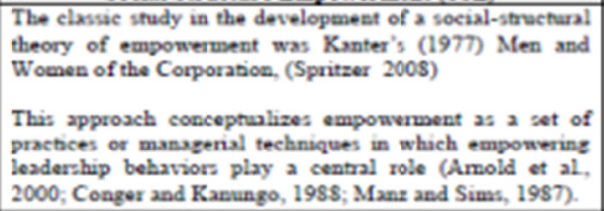 & $\begin{array}{l}\text { The paper that researchers to think differently about empowerment was a } \\
\text { conceptual piece by Conger and Kanungo (1988). They argued that a } \\
\text { social-structural perspective was incomplete because the empowering } \\
\text { managerial practices would have little effect on employees if they lacked } \\
\text { a sense of self-efficacy. } \\
\text { The focus of this approach is on PE as a cognitive motivational state } \\
\text { relecting individuals' paychological reactions to empowvering techniques } \\
\text { and leadership bebaviors (Spreitzer, 1995; Thomas and Velthouse, 1990) }\end{array}$ \\
\hline Koot Theory & $\begin{array}{l}\text { The SSE is rooted in theories of social exchange and rocial } \\
\text { power (Spreitzer 2008) }\end{array}$ & $\begin{array}{l}\text { PE was based on the organizational theones of participative management } \\
\text { and employee involvement of Cotton (1993) and Warner (1994). }\end{array}$ \\
\hline Empowerment Level & $\begin{array}{l}\text { More macro and focuses on the social-structural (or } \\
\text { contextual) conditions that enable empowerment in the } \\
\text { workplace (Spreitzer, 2005) }\end{array}$ & $\begin{array}{l}\text { More micro in orientation and focuses on the paychological experience } \\
\text { of empowerment at work (Spreitzer 200\$). }\end{array}$ \\
\hline Mais Foce: & $\begin{array}{l}\text { Focus on between empowering struchures, policies, and } \\
\text { practices (Spreitzer 200\$). }\end{array}$ & Focus on perceptions of empowerment (Spreitzer 200\$). \\
\hline Way of Empowerment & $\begin{array}{l}\text { Employees at low levels of the organizational bierarchy } \\
\text { can be eumpowered if they have access to opportunity. } \\
\text { information, support and revources. (Spreitzer, 2008) }\end{array}$ & $\begin{array}{l}\text { Set of pryehological states that are secestary for individuals to feel a } \\
\text { sense of control in relation to their work. Focused on bow employees } \\
\text { experience their work. The personal beliefs that employees have about } \\
\text { their role in relation to the organization. }\end{array}$ \\
\hline $\begin{array}{l}\text { The essence of } \\
\text { Empowerment }\end{array}$ & Shaning of power and Decision making & $\begin{array}{l}\text { Expenence of Manning , Competency, Self-determination and Impact } \\
\text { (Spreitzer 2008) }\end{array}$ \\
\hline Basic Model Author & Kanter (1977) & Thomas and Velthouse $(1990)$ \\
\hline Example Model & The CWEQ II (Lsochinger et al. 2001) & Spreitzer $(1995)$ \\
\hline \multirow[t]{2}{*}{ Dimencion: } & Based on Laschinger et al, 2001 & Bazed on Spreitzer (1995) \\
\hline & $\begin{array}{l}\text { Opportunity } \\
\text { Information } \\
\text { Support } \\
\text { Resources } \\
\text { Informal power } \\
\text { Formal power }\end{array}$ & $\begin{array}{l}\text { Mexning } \\
\text { Competescy } \\
\text { Self-Determaination } \\
\text { Impact }\end{array}$ \\
\hline
\end{tabular}

\section{Copyrights}

Copyright for this article is retained by the author(s), with first publication rights granted to the journal.

This is an open-access article distributed under the terms and conditions of the Creative Commons Attribution license (http://creativecommons.org/licenses/by/4.0/). 